\title{
Interaction of early diet and the development of the immune system
}

\author{
Angel Gil ${ }^{1 *}$ and Ricardo Rueda ${ }^{2}$ \\ ${ }^{1}$ Department of Biochemistry and Molecular Biology, University of Granada, Campus de \\ Cartuja, 18071 Granada, Spain \\ ${ }^{2}$ Research and Development Department, Ross Products Division, Abbott Laboratories, \\ Camino de Purchil 68, Granada, Spain
}

\begin{abstract}
The present review focuses on the specific effects of nutrients on the development of the immune system in early life. There is a big gap regarding the specific mechanisms that regulate immunity at the intestinal level and their impact in the systemic immune function. For this reason, during the last few years there has been great interest in ascertaining the mechanisms that regulate the intestinal immune function, as well as to understand how specific nutrients interact with the gut-associated lymphoid tissue. We have reviewed this topic with special emphasis on how human milk, and its components, influence the early development of intestinal immunity in breast-fed infants compared with formula-fed infants. Interactions between nutrients and intestinal microbiota have also been reviewed. Some micronutrients such as nucleotides and gangliosides, which are present in human milk and also in most foods, are able to influence immune functionality at very low concentrations. The specific action of these micronutrients on some parameters of immunity, as well as their potential mechanisms of action, have been considered in detail. However, there are limited data on how other specific nutrients, namely protein and non-protein N-containing compounds, lipids, carbohydrates, and others, such as minerals, vitamins, fibre, non-nutritional dietary compounds (flavonoids, carotenoids, phyto-oestrogens, etc), influence immunity. In the present review we have provided data regarding the potential effects of these compounds on the immune response in early life. The increasing use of functional foods by the public to improve their general health and prevent the incidence of chronic diseases has become a major area of interest within the nutrition community. Of the many functional foods available, probiotics have been most studied in infancy and childhood, particularly with regard to the prevention of allergic diseases. Infant formulae and fermented milks containing large quantities of probiotics are produced and
\end{abstract}

\footnotetext{
Abbreviations: GD, disialoganglioside; GI, gastrointestinal; Ig, immunoglobulin; IL, interleukin; LGG, Lactobacillus rhamnosus GG; PG, prostaglandin; PUFA, polyunsaturated fatty acids; TGF, transforming growth factor; Th, T-helper; TLR, toll-like receptor; TNF, tumour necrosis factor.

*Corresponding author: Professor Angel Gil, fax +34 958 248960, email agil@ugr.es
} 
consumed by Europeans and in other industrialized countries. In the present review we cover the clinical effects of probiotics in preventing disease during early life, as well as the potential mechanisms of interaction between probiotics and the gastrointestinal tract.

\section{Immunity: Breast-feeding: Infant formulae: Functional foods: Gastrointestinal tract}

\section{Introduction}

Over the last few years, the study of the specific effects of different nutrients and of different types of feeding on the immune system has grown in interest. Although it is not well known if there are critical periods of life during which the inclusion of a specific ingredient in the diet could be especially beneficial for the development and maintenance of the immune system, it seems clear that infancy constitutes a period of special attention. In this sense, differences between the maturation of the immune system in breast-fed infants compared with formula-fed infants have been reported.

Considering the potential influence of nutrients on the immune system it is important to point out that the first contact between food and the immune system takes place at the intestinal level. Moreover, the development and functional mechanisms of the regional immune system in the gastrointestinal (GI) tract are relatively independent of those of the systemic immunity (Kagnoff, 1993). Furthermore, the interaction of different factors, such as intestinal microbiota and nutrients at the local level, can influence the inner regulatory mechanisms of the intestinal immune function, especially during the first year of life.

The gut-associated lymphoid tissue is a secondary lymphoid organ, which is in charge of processing antigens that interact with the intestinal mucosa and of disseminating the immune response. Antigens present in the intestinal lumen are transported into the Peyer's patches through $\mathrm{M}$ cells, which are located between the enterocytes in the epithelium. Once in the Peyer's patches, antigens interact with antigen-presenting cells, which present them to immature $\mathrm{B}$ and $\mathrm{T}$ cells located in the germinal centres and in the inter-follicle regions. These immature $\mathrm{B}$ and $\mathrm{T}$ cells, after being activated by antigens, are drained by the regional lymph nodes, and migrate through the thoracic duct to the bloodstream. Finally, after recirculating for several days, they differentiate into mature effector cells migrating to the lamina propria and to the intestinal epithelium. Thus, three main lymphocyte populations (lymphocytes from Peyer's patches, lymphocytes from the lamina propria, and intra-epithelial lymphocytes) can be distinguished in the intestine (Fig. 1).

The gut immune system has a more difficult task than most other mucosae because it must distinguish not only between self and non-self but also between potentially dangerous foreign antigens and common harmless foodstuffs to which it is constantly exposed (Brandtzaeg \& Nilssen, 1995; Morales et al. 1996). The local intestinal immune system is capable of not only a rapid powerful defence against invading organisms but also of active specific suppression of responses against non-invasive antigenic material to avoid potentially damaging reactions to these antigens (Hanson et al. 1995). The mechanism that assures this regulated balance is not well known but involves, at least in part, the careful selection of appropriate lymphoid populations and the orderly expression of cytokines (Morales et al. 1996). Most of the intestinal lymphocytes, especially those located in the lamina propria and intra-epithelial lymphocytes, 

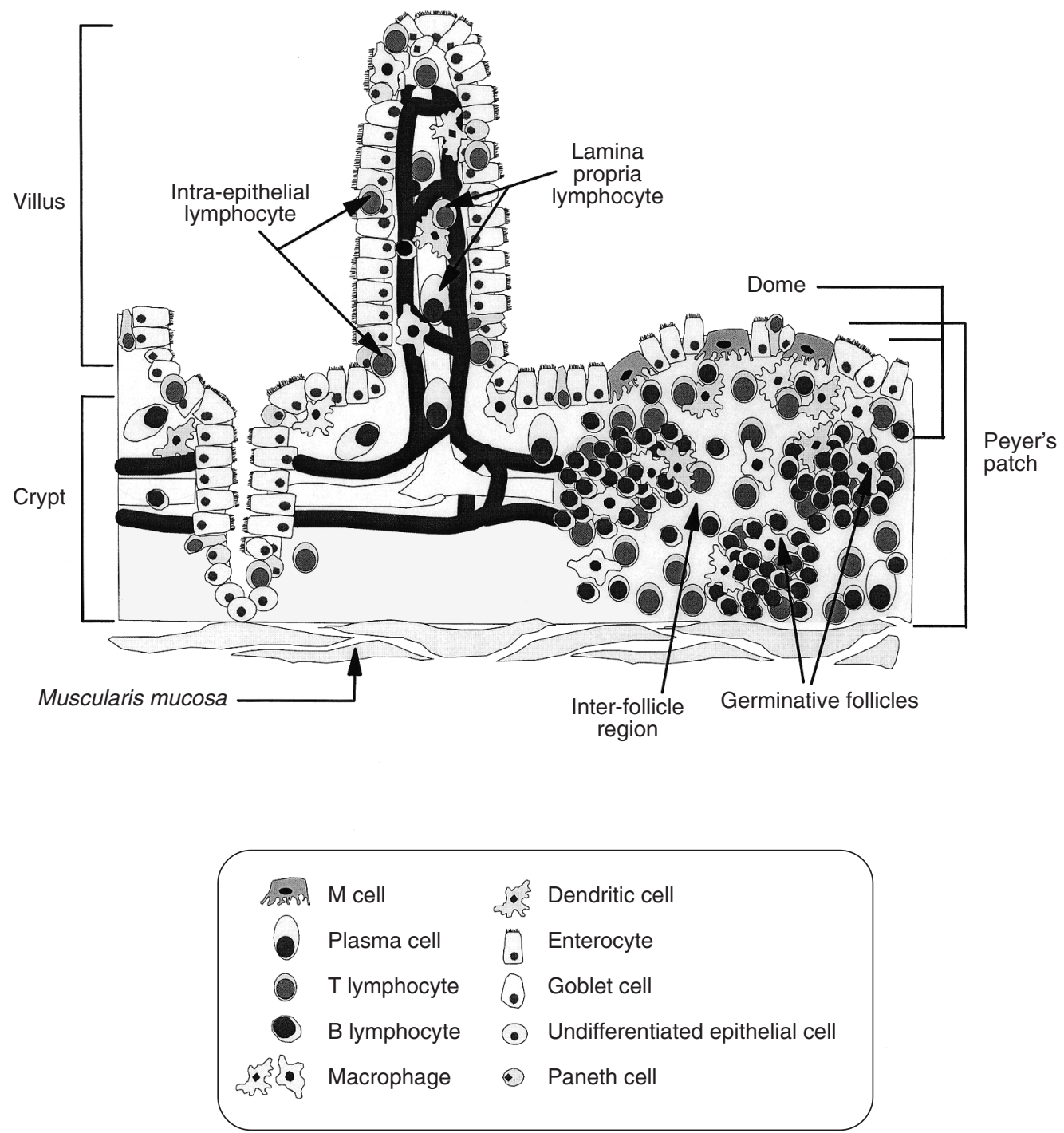

Fig. 1. Schematic view of the gastrointestinal lymphoid associated tissue (reproduced with permission from Vázquez (2000)).

have a high grade of differentiation and maturation, and because of it are submitted to a pronounced state of chronic activation. In addition, the ontogeny for some of the intestinal lymphocytes is different from that for systemic lymphocytes. For instance, some of the intraepithelial lymphocytes mature directly in the intestine and not in the thymus, and some plasmic cells have a precursor population of B cells located in the peritoneal cavity, but not in the bone marrow. All these characteristics suggest that the development and expression of the regional immune system in the GI tract is relatively independent of systemic immunity (Kagnoff, 1993). Table 1 shows the main characteristics of the intestinal immune system that make it different from the systemic one. 
Table 1. Main characteristics of the intestinal immune system

1. Submitted to a constant and massive stimulation by two main types of antigens:

(a) antigens present in the surface of micro-organisms, for which it has to develop an aggressive response

(b) antigens present in foods, for which it has to develop a tolerant response

2. Intestinal lymphocytes, especially those located in the lamina propria and in the epithelium, exhibit a high rate of maturation and differentiation, usually maintaining a status of chronic activation

3. Different ontogenia:

(a) a big subpopulation of intra-epithelial lymphocytes are thymus-independent; they mature directly in the intestine

(b) some of the plasma cells located in the lamina propria derive from a precursor subpopulation of B1 cells located in the peritoneal cavity

4. The main mechanism of defence at intestinal level is the secretion of immunoglobulin A to the intestinal lumen to promote the exclusion of antigens which penetrate through the gastrointestinal tract

Interactions at the local level profoundly influence the systemic immune response, in part because of intrinsic differences in these systems, and also because of different requirements for optimal function. Interaction with normal bacteria of the GI tract may be seen as a model of how the system has evolved and provides clues to the restoration of balance in the immunocompromised host (Cunningham-Rundles \& Lin, 1998). Nutritional balance is essential for the development of the immune system at the level of organs and cells. Nutrients influence host defence during the acute process of immune response because this requires immediate changes, involving cell activation, proliferation and differentiation. These processes are in turn dependent on cytokine and growth factor production and secretion. Specific nutrients, for instance nucleotides, gangliosides, polyunsaturated fatty acids (PUFA), some minerals such as $\mathrm{Fe}$ and $\mathrm{Zn}$, etc, also appear to act as critical cofactors in the expression of immune response (Rueda \& Gil, 2000; Gil, 2002). In addition, because microbes directly affect digestion and act as nutrient providers in the GI tract, these relationships are tightly linked in a mutually interactive fashion through the function of the GI immune system.

Although the immune response to GI microbiota is usually regarded as defensive, it now seems likely that an important consequence of this interaction is the production of growth factors, cytokines and regulatory molecules, which selectively control regional immune function. In addition, normal intestinal growth may be mediated through $\mathrm{T}$ cell activation by food substances and microbial flora (Elmer et al. 1996). It has also been suggested that macromolecular transport and solvent drag effects probably allow frequent stimulation and activation of the gut immune system even in the absence of an infecting agent or obvious barrier damage. Stimulating a bacterial immune response might offer a means of restoring the mucosal barrier. Although some micro-organisms found in the GI tract are opportunistic and may become pathogenic, others, such as lactobacilli, are thought to promote the development of the mucosal barrier by stimulation of immune response (Isolauri et al. 1993). Additionally, in some instances systemic immune response may be directly augmented by dietary addition of lactobacilli (Schiffrin et al. 1995). In the future it may be possible to use a combination of nutrients and selected immune-enhancing bacteria to promote the long-term health of the GI immune system (Cunningham-Rundles \& Lin, 1998). Moreover, supplementation of infant formulae with probiotics has been shown to have a beneficial effect on the prevention of allergy development, especially in individuals predisposed to suffer from this type of pathology (Isolauri, 2001). This topic will be described in more detail later in the present review. 


\section{Breast-feeding $v$. formula-feeding and the immune system}

Breast-feeding has beneficial effects on the nutritional status of the infant, and also protects against a range of infections and infection-related diseases (Wold \& Hanson, 1994; Kakai et al. 1995). Although the mechanisms of protection are not well known, a modulation of the microbiology, physiology and immunology of the infant may be involved (Pabst et al. 1997). Newborn infants are highly susceptible to infection during early life, which, in large part, is the result of delayed development of the immune function. A supply of factors in breast milk may, therefore, be critical for the infant and could explain the markedly lower incidence of necrotizing enterocolitis in infants fed breast milk compared with infants fed formula (Lönnerdal, 2000).

\section{Components of breast milk and their key role}

Breast milk contains several components that directly or indirectly participate in the immune function of the breast-fed infant. There are considerable amounts of antibodies, with secretory immunoglobulin (Ig) A being the predominant class (Goldman et al. 1982). The secretory IgA antibodies in human milk are known to recognize a wide variety of micro-organisms, including bacterial pathogens such as Escherichia coli, Vibrio cholerae, Haemophilus influenzae, Streptococcus pneumoniae, Clostridium difficile, and salmonella, viruses such as rotavirus, cytomegalovirus, HIV, influenza virus, and respiratory syncitial virus, as well as yeasts like Candida albicans (Goldman, 1993). The specificity of these antibodies is believed to be acquired by antigen-triggered migration of B cells from Peyer's patches in the small intestine tract, and from lymphoid tissue in the respiratory tract, to the lamina propria of the mammary gland, through the 'enteromammary' pathway. The newborn, whose immune system is relatively immature, thus gains protection against the same mucosal pathogens to which the mother is exposed (Telemo \& Hanson, 1996). Specifically, the production of secretory IgA is low during early infancy (Rognum et al. 1992), and thus breast-fed infants acquire these antibodies orally and derive protection against both enteric and respiratory pathogens, whereas formulafed infants do not.

Anti-idiotypic IgA antibodies may also confer immunity to the newborn infant. If these antibodies survive in the GI tract, they may elicit mucosal antibody responses targeted toward wild strains of enteric viruses, such as polio viruses (Lönnerdal, 2000). The finding of polio anti-idiotypic antibodies in colostrum and mature breast milk is in agreement with studies showing better vaccine responses in breast-fed than in formula-fed infants (Hahn-Zoric et al. 1990; Pabst \& Spady, 1990), which may be the result of the additional exposure of the breastfed infant to the anti-idiotypes present in the milk.

Leucocytes are present in breast milk, particularly in colostrum and during early lactation. Colostrum contains considerable numbers of macrophages and activated CD8-positive T lymphocytes (Wold \& Hanson, 1994). Since macrophages display potent immunosuppressive activity and human breast milk leucocytes fed to baboons have been shown to be taken up into the infant's circulation, colostral macrophages could function as immunosuppressors (Wold \& Adlerberth, 1998); CD8-positive milk lymphocytes could also down regulate infant T cell functions. The transient tuberculin positivity, which is seen in breast-fed infants born from tuberculin-positive mothers, but not in bottle-fed infants or infants breast-fed by tuberculin-negative mothers, constitutes indirect evidence that functionally active $\mathrm{T}$ cells are taken up from the 
maternal milk by the infant during the first days of life (Wold \& Adlerberth, 1998). Neutrophils dominate, comprising about 40-60\% of the cells found in human milk. They have low motility and do not respond to chemo-attractants, which indicates that they may also be activated, as activated neutrophils become unresponsive to some chemo-attractants (Keeney et al. 1993). Although the function of activated neutrophils in breast milk is unknown, they might compensate for the poor capacity of the newborn to recruit blood neutrophils to sites of inflammation in the GI tract (Keeney et al. 1993).

Lactoferrin, which is found in large quantities $(1.5 \mathrm{~g} / \mathrm{l})$ in breast milk, has a role in defence against infection and immunotropic properties (Adamic \& Wlaszczyk, 1996). It has been suggested that the ability of lactoferrin to bind an excess of Fe ions, needed for growth of microorganisms and tumours, represents an important defence mechanism in man. Lactoferrin, in addition, may contribute to the protection against pathogens and their metabolites by enhancing phagocytosis, cell adherence and controlling release of pro-inflammatory cytokines such as interleukin (IL)-1, IL-6 and tumour necrosis factor (TNF) $\alpha$ from macrophages stimulated with bacterial products (Adamic \& Wlaszczyk, 1996; Mattsby-Baltzer et al. 1996). Lactoferrin also diminishes the damaging effects of free radical release and it possesses interesting immunotropic properties with regard to immature $\mathrm{T}$ and $\mathrm{B}$ cells by promoting phenotypic and functional maturation of these cells. Moreover, lactoferrin controls the effector phase of the cellular immune response and inhibits manifestations of auto-immune response in mice (Adamic \& Wlaszczyk, 1996). It has also been reported that bovine lactoferrin induces both mucosal and systemic immune responses, enhancing $\operatorname{IgG}$ and $\operatorname{IgA}$ secretion in Peyer's patches and in spleen from mice. It has been proposed that lactoferrin could act as an immunostimulating factor on the mucosal immune system and that activation of the mucosal immune system is dependent on the ability of lactoferrin to bind to the intestinal mucosa (Debbabi et al. 1998). Lactoferricin, which is a peptide located at the N-terminal end of bovine and human lactoferrin, has shown strong bactericidal effects both in vitro and in vivo (Teraguchi et al. 1995).

Lysozyme is present in human milk in unusually high concentrations and is an active enzyme $(0 \cdot 1-0 \cdot 3 \mathrm{~g} / \mathrm{l})$. It can degrade the cell walls of gram-positive bacteria and could have synergistic effects with lactoferrin (Lönnerdal, 2000).

Human breast milk contains extremely high quantities (4-6 g/l) of complex oligosaccharides, which are almost totally lacking in cows' milk (Kunz \& Rudolff, 1993). These oligosaccharides consist of a lactose core substituted with $\mathrm{N}$-acetyl glucosamine, galactose, fucose and sialic acid in various linkages and positions, yielding a total of more than a hundred different compounds (Kunz \& Rudolff, 1993). The predominant species are lacto- $N$-tetraose, lacto- $N$ fucopentaose, sialyl-lactose, and disialyl-lacto- $N$-tetraose (Stahl et al. 1994). Since these oligosaccharides contain structures that may function as ligands for leucocyte adhesion molecules, it is possible that the presence of such oligosaccharides in the circulation could affect leucocyte integrin expression (Kunz \& Rudolff, 1993), thus allowing leucocyte rolling and homing into specific sites of lesion or infection. The role of human milk oligosaccharides preventing the infection by different micro-organisms, such as $H$. influenzae, S. pneumoniae, $V$. cholerae, E. coli, C. jejuni, and rotavirus, has also been reported, acting as false receptors at the intestinal level (Holmgren et al. 1983; Korhonen et al. 1985; Andersson et al. 1986; Cravioto et al. 1991; Yolken et al. 1992; Cervantes et al. 1995).

Another component of human breast milk, epidermal growth factor, may enhance the maturation of the gut epithelial barrier, leading to a decreased uptake of foreign protein antigens in the breast-fed infant (Udall et al. 1981), and hence to decreased immune stimulation. Other components of breast milk, such as $\kappa$-casein, digestive fragments of casein subunits, lactoperoxidase and polyamines, have been shown to have antimicrobial and/or immunostimulatory 
activity in vitro and in vivo, although human studies are largely lacking (Lönnerdal, 2000). There are other micronutrients present in human milk, namely nucleotides and gangliosides, which have been demonstrated to have an immunoregulatory role. This topic will be widely discussed later. However, these micronutrients should be mentioned here because although their concentration in milk is relatively low their biological effects on the neonatal intestine are very important. It is also important to mention that nucleotides have been incorporated in infant formulae worldwide. Table 2 summarizes the role of some relevant human milk components in systemic and mucosal immunity.

\section{Immune function in breast-fed $\mathrm{v}$. formula-fed infants}

A number of studies have clearly demonstrated that the base-line activation of lymphocytes is higher in bottle-fed than in breast-fed infants, as reflected by a higher integrin expression and proliferative response in the absence of antigen (Wold \& Adlerberth, 1998). This activation could be the result of the exposure of bottle-fed infants to a larger variety of food proteins. It is, however, unlikely that simple food antigens would give rise to such a marked and persistent lymphocyte activation. At least two other possibilities should be considered. First, the presence of anti-inflammatory and anti-proliferative factors in breast milk may decrease the activation of the immune system of the breast-fed infant. Second, the bottle-fed infant could have a more varied intestinal microbiota and be exposed to a greater variety of microbial products capable of stimulating the immune system. The two possibilities are, of course, not mutually exclusive (Wold \& Adlerberth, 1998).

Breast milk also contains cytokines that might modulate the infant's immune system (Wold \& Hanson, 1994). Animal experiments have shown that cytokines survive and retain biological activity during the passage through the GI tract and that they may even be taken up into circula-

Table 2. Role of some relevant human milk components in systemic and mucosal immunity

\begin{tabular}{ll}
\hline Component & \multicolumn{1}{c}{ Role } \\
\hline $\begin{array}{l}\text { Secretory immunoglobulin A } \\
\text { Lactoferrin }\end{array}$ & $\begin{array}{l}\text { Specific mucosal antibodies against a number of bacteria, yeasts and viruses } \\
\text { Defence against infection and immunotropic properties by binding iron } \\
\text { Control of effector phase of cellular immune response } \\
\text { Enhances mucosal and systemic immune responses }\end{array}$ \\
Lysozyme & $\begin{array}{l}\text { Degrades cell walls of Gram-positive micro-organisms and has synergistic } \\
\text { effect with lactoferrin }\end{array}$ \\
Epidermal growth factor & $\begin{array}{l}\text { Enhances maturation of the gut epithelial barrier leading to decreased uptake } \\
\text { of antigens }\end{array}$ \\
Casein peptides & $\begin{array}{l}\text { Antimicrobial and immunostimulatory activity in vivo and in vitro } \\
\text { Lactoperoxidase }\end{array}$ \\
Antimicrobial and immunostimulatory activity in vivo and in vitro \\
Polyamines & Modulation of the infant immune system \\
Nucleotides & Antimicrobial and immunostimulatory activity in vivo and in vitro \\
& Enhance lymphocyte maturation, activation and proliferation. Modify lympho- \\
cyte subpopulations. & Modulate immunoglobulin production \\
Complex oligosaccharides & False bacterial receptors in the intestine \\
Ligands which affect leucocyte integrin expression & Antimicrobial activity in vitro and in vivo. Enhance the process of proliferation, \\
activation and differentiation of T lymphocytes
\end{tabular}


tion and affect immune functions (Rollwagen \& Baqar, 1996). Large amounts of both inflammatory (IL-1, TNF- $\alpha$ ) and anti-inflammatory (transforming growth factor (TGF)- $\beta$, IL-10) cytokines are present in breast milk (Wold \& Hanson, 1994). TGF- $\beta$ and IL-10 exert profound down regulating effects on lymphocyte proliferation, as does prostaglandin (PG) $\mathrm{E}_{2}$, which is also produced by breast-milk macrophages. Human milk also contains soluble cytokine and chemokine receptors and receptor antagonists, which could contribute to its anti-inflammatory properties (Buescher \& Malinowska, 1996). Other cytokines are involved in B cell maturation and differentiation. TGF- $\beta$ can cause isotype switching to $\operatorname{IgA}^{+} \mathrm{B}$ cells and IL- 6 can promote the synthesis of $\operatorname{IgA}$ and $\operatorname{IgM}$, as well as the terminal differentiation of $\operatorname{Ig} \mathrm{A}^{+}$cells to $\operatorname{IgA}$-producing plasma cells (Strober \& Ehrhardt, 1994). All these immunomodulatory agents help to boost parts of the infant's immune system that have not been fully developed and aid in the proper response to challenges to the system (Lönnerdal, 2000).

Breast-feeding has also been shown to enhance secretory antibody responses to parenteral and oral vaccines. Breast-fed infants had significantly higher salivary and stool secretory IgA responses to tetanus toxoid and polio than formula-fed infants (Hahn-Zoric et al. 1990). The enhanced immune response to vaccines is still observed in older children who were breast-fed as infants (Hahn-Zoric et al. 1990; Pabst \& Spady, 1990). In addition, breast-fed infants have been shown to have long-term protection against $H$. influenzae infection (Hanson et al. 1995).

An issue that remains unclear is the impact of nutritional status on the specific immune responses that develop following immunization (Solomons \& Keusch, 2000). However, given the potential effect of nutrition on immune responses, including the responses to vaccines, some consideration has been given to the use of particular nutrients as potential 'adjuvants' for the immune response at the time of immunization. A number of trials have tested a protein supplement or vitamin A given with a vaccine in an attempt to enhance the immune response, claiming the use of oral vitamin A as the 'seventh' immunization in the Expanded Programme of Immunization six-vaccine scheme (Solomons \& Keusch, 2000). Likewise, the study reported by Pickering et al. (1998) showing that nucleotide supplementation of cows'-milk formula nearly doubled the responsiveness to $H$. influenzae type b polysaccharide in infants receiving Hib-conjugate vaccine, and diphtheria, tetanus toxoids, and oral polio virus immunization, could be another example of the above-mentioned concept.

The induction of immunological tolerance, by the transfer of immunocytes in breast milk, may also explain the long-term protective effect of breast-feeding on the decreased risk of developing auto-immune type 1 diabetes (Dosch et al. 1993), atopic dermatitis (Sigurs et al. 1992), lymphomas (Davis et al. 1988) and Crohn's disease (Koletzko et al. 1989), as well as the improved survival of maternal renal transplants (Campbell et al. 1984). These reports suggest that the initial handling of antigens by the mucosal immune system in the gut is critical in the development of effective immunity and subsequent immune responses. The modifying effect of breast milk is important in determining not only protective immunity, but also in reducing adverse immune responses that lead to atopy and to auto-immune and lymphoproliferative disorders (Cripps \& Gleeson, 1999).

It has been recently reported that the consumption of cows' milk, in particular the wide use of cows'-milk-based infant formula, might be a risk factor for the development of insulindependent (type 1) diabetes mellitus. Indeed, several epidemiological studies have concluded that the introduction of cows'-milk-based infant formula before the age of 3 months is associated with a higher risk of onset of type 1 diabetes later in life (Kolb \& Pozzilli, 1999). Nevertheless it should be pointed out that these are associations, not proven cause and effect. It appears that there is nothing unique about cows' milk but that many different sources of complex proteins might be diabetogenic, as judged from animal and some epidemiological studies. 
Critical factors are probably the immunoregulatory state of the gut and whether the encounter with dietary antigens leads to an oral tolerance response or to sensitization and possible loss of self-tolerance to cross-reacting epitopes (Kolb \& Pozzilli, 1999).

The role of duration of breast-feeding and/or avoidance of cows'-milk-based formulae during early life on the development of atopic disease (Lönnerdal, 2000) has been a subject of considerable controversy during the last few years; this topic will be discussed later.

Finally it is important to emphasize that there are profound temporal changes of immunological activity during infancy. It is suppressed during breast-feeding, activated with weaning, and later undergoes intrinsic down regulation after weaning (Cummins \& Thompson, 1997). TGF- $\beta$ in breast milk may mediate this immunosuppressive effect. The systemic immune system of neonates may be subject to a preponderant T-helper (Th) $2 v$. Th1 immune response, while the mucosal immune system, particularly of the GI tract is up regulated with physiological inflammation during infancy. Weaning is associated with a peak of intestinal immune activation, which includes mucosal mast cells and $\mathrm{T}$ cells. The physiological effects of this activation are promotion of epithelial growth of the small intestine and initial activation of mechanisms leading to subsequent down regulation of the physiological heightened immune activity. This coincides with the development of mucosal (oral) tolerance to food and bacterial antigens (Cummins \& Thompson, 1997).

\section{Influence of specific nutrients on the immune system}

In this section the main findings in the field are summarized, focusing on the influence of specific nutrients on the gut immune system.

\section{Protein nitrogen}

Dietary protein is important for the maintenance of the immune system and also influences the response to infection through several mechanisms (Millward, 1999). One mechanism is the maintenance of gut barrier function, through provision of threonine, cysteine, and other amino acids involved in the synthesis of mucus glycoproteins. Another is maintenance of general immunocompetence through provision of specific amino acids for synthesis of cellular proteins of the immune system. In particular, glutathione, a key free radical scavenger synthesized from glutamate (glutamine), glycine and cysteine, is depleted in the intestinal mucosa in proteinrestricted animals. The main effect of protein supplementation is to increase the rate of acquisition of immunity and increase resistance to re-infection and this has been associated with an enhanced cellular immune response in the GI mucosa (Coop \& Holmes, 1996).

The influence of protein intake on glutamine levels is also a possible factor. Glutamine is strongly concentrated in skeletal muscle and appears to play a specific role in maintaining the function of rapidly proliferating cells such as lymphocytes and mucosal enterocytes. Under conditions of infection and trauma, muscle concentrations of glutamine fall and this may limit the provision of glutamine for the immune system or to the splanchnic bed, where it appears to play a specific role in maintaining glutathione synthesis during trauma. The positive effect of $\mathrm{L}-$ glutamine and glycyl-L-glutamine on the prevention of small intestinal gut-associated lymphoid tissue atrophy induced by intravenous administration of total parenteral nutrition has been recently reported ( $\mathrm{Li}$ et al. 1998). Total parenteral nutrition results in small-intestinal gut-associated lymphoid tissue atrophy, and lowers small-intestinal IgA levels; however, isonitrogenous 
supplementation of total parenteral nutrition with $2 \%$ glutamine or glycyl-L-glutamine attenuates these changes. Likewise, the immunomodulatory capacity of glutamine improving the immunological situation in the gut under endotoxaemia has also been recently reported (Manhart et al. 1999). Supplementation of the diet with glutamine $(0 \cdot 72 \mathrm{~g} / 100 \mathrm{~kJ} ; 3 \mathrm{~g} / 100 \mathrm{kcal})$ induced an increase of B cell and T-CD4 cell subpopulations in Peyer's patches from endotoxin-challenged mice.

Provision of arginine is also important in relation to the immune system. This may be related to its role as a precursor for NO synthesis, a key regulator of a variety of physiological processes that include the regulation of macrophage killer function, interactions between macrophages, and lymphocyte adhesion and activation (Evoy et al. 1998). Taurine, a B-amino sulfonic acid derived from cysteine, appears to be an effective scavenger of peroxidation products, and has also been related to a role in the immunomodulation of gut-associated lymphoid tissue, especially during postnatal development (Redmon et al. 1998).

\section{Non-protein nitrogen}

Within the non-protein $\mathrm{N}$ compounds, nucleotides have clearly been demonstrated to play an immunoregulatory role. Nucleotides are normal components of the human diet from birth onwards. Although a nucleotide-free diet has not been related to any particular deficiency disease, dietary nucleotides for infant feeding and for parenteral use have been reported to be beneficial for lipid metabolism, immunity and intestinal and liver regeneration (Sánchez-Pozo et al. 1998; Gil, 2002).

Rapidly proliferating tissues, such as the immune system or the intestinal mucosa, are not able to fulfil the needs of cellular nucleotide requirements exclusively by de novo synthesis and they therefore preferentially utilize the salvage pathway, salvaging nucleosides and nucleobases from blood and diet. An exogenous supply of these compounds through the diet may be essential to sustain growth and to maintain cellular function in these tissues (Uauy et al. 1996).

Nucleotides have been involved in different aspects of the systemic immune response, such as lymphocyte maturation, activation and proliferation, modification of lymphocyte subpopulations, the phagocytic activity of macrophages, the delayed hypersensitivity and allograft and tumour responses, and the modulation of immunoglobulin production (Rueda \& Gil, 2000). Likewise, nucleotides are thought to be involved in the defence against infection. One of the mechanisms by which nucleotides lower the incidence of infection is the modulation of the intestinal biota (Gil et al. 1986). However, the specific action of nucleotides in stimulating the immune system at the intestinal level should also be taken into account. This is supported by recent clinical studies reporting a lowered incidence of acute diarrhoea in infants fed nucleotide-supplemented formulae in developing (Brunser et al. 1994) as well as in developed countries (Lama \& Gil-Alberdi, 1998; Pickering et al. 1998).

Regarding the possible mechanism of action of dietary nucleotides, it has been proposed that dietary nucleotides exert effects upon cellular immune function by acting on the Th and T-inducer population, with the predominant effect on the initial phase of antigen processing and lymphocyte proliferation (Van Buren et al. 1985). Recent clinical data suggest that dietary nucleotides enhance immune cell maturation in infants by raising memory and effector $\mathrm{T}$ cell population while decreasing naive $\mathrm{T}$ cell populations (Buck et al. 2001). In addition, exogenous nucleotides may modulate Th cell-mediated antibody production (Jyonouchi et al. 1994). Moreover, it has been suggested that dietary nucleotides may favour the balance of T-cell differentiation to Th1 or Th2 cells. Some reports suggest that they can affect both Th cell popula- 
tions (Jyonouchi et al. 1996; Manzano et al. 2001). However, it has also been reported that they mainly favour Th1 response (Jyonouchi et al. 2001).

The molecular mechanisms by which dietary nucleotides modulate the immune system are virtually unknown. It has been suggested that the small intestine plays a key role in the regulatory effects of nucleotides upon the immune response. There are a number of studies demonstrating that enterocytes are antigen-presenting cells (Bland \& Warren, 1986) and that they are able to produce important cytokines, which may modulate the processes of intestinal lymphocyte activation, proliferation, and differentiation (Shirota et al. 1990). Dietary nucleotides have been shown to enhance both the gene and protein expression of IL- 6 and IL-8 by fetal smallintestinal explants challenged with IL-1 $\beta$, in a dose-dependent fashion (Tanaka et al. 1996). Our group has recently reported that dietary nucleotides modify murine intestinal lymphocyte subpopulations at weaning (Manzano et al. 1999). In this work we observed that developmental changes in expression of most of the antigens in the lymphocyte populations analysed were accelerated in the animals fed on a diet supplemented with nucleotides, indicating that dietary nucleotides may affect the maturation of intestinal lymphocytes, and consequently, the development of the intestinal immune function.

\section{Lipids}

The fatty acid composition of cell membranes, including that of lymphocytes, can be modified by dietary fatty acid manipulation, and as a result, dietary lipids can play an important role in the immune response (Keusch, 1999).

PUFA ( $n-6$ and $n-3)$, which are present in human milk and some infant formulae in relatively high amounts, are involved in the regulation of the inflammatory response. However, experimental and clinical studies have shown that the immune response can be modulated by nutritional interventions, mainly with $n$-3 PUFA supplements (Calder, 1997; Hughes \& Pinder, 2000; Sweeney et al. 2001; Terada et al. 2001). Alterations include changes in the production of immunological mediators (Calder, 1997) and lymphocyte proliferation in response to mitogens (Cerridan \& Wilson, 1999). Data from in vivo and in vitro studies indicate that lymphocyte proliferation is reduced in response to relatively high levels of $n-3$ PUFA (Calder, 1997; Terada et al.2001). However, a number of studies show that feeding moderate amounts of PUFA is not immunosuppressive, but may enhance immune function. For instance, docosahexaenoic acid enhances levels of memory and effector $\mathrm{T}$ cells in preterm infants (Field et al. 2001). The proliferation of monocytic cell lines and human antigen-presenting cell function in vitro can also be inhibited by $n$-3 PUFA (Sanderson et al. 1997; Hughes \& Pinder, 2000). Dietary supplementation with $n-3$ PUFA inhibits the intensity of expression of major histocompatibility class II antigens in human monocytes, illustrating a potential mechanism by which $n-3$ PUFA could suppress cell-mediated responses (Hughes \& Pinder, 2000). They also reduce the expression of adhesion molecules (ICAM-1 and LFA-1) and indeed affect the movement of lymphocytes and monocytes between body compartments and perhaps into areas of inflammatory activity (Hughes \& Pinder, 1997).

Many of the effects of $n-3$ PUFA on the immune system are mediated by changes in the production of eicosanoids. Dietary supplementation with $n-3$ PUFA leads to the formation of the less biologically active leucotriene $\mathrm{B}_{5}$ at the expense of the pro-inflammatory leucotriene $\mathrm{B}_{4}$. $\mathrm{PGE}_{2}$ production is consistently reported to decline following $n$-3 PUFA supplementation. $\mathrm{PGE}_{2}$ inhibits the production of the pro-inflammatory mediators IL-1 and TNF- $\alpha$ by macrophages, IL-2 production and lymphocyte proliferation, and modulates the expression of 
major histocompatibility class II receptors by macrophages. It has also recently been reported that cyclo-oxygenase-2-dependent arachidonic acid metabolites are essential modulators of the intestinal immune response to dietary antigens (Newberry et al. 1999). Specifically, these authors have demonstrated that lamina propria mononuclear cells can influence the immune response to ingested non-pathogenic antigens through arachidonic acid metabolism by a cyclooxygenase-2-dependent mechanism. This intestinal regulatory pathway represents an essential mechanism for maintaining intestinal immunological homeostasis, and disease- or drug-induced alterations in the production of cyclo-oxygenase-2-dependent arachidonic acid metabolites could have adverse effects on the developing intestinal immune response to luminal antigens.

Different studies have shown that $n$-3 PUFA can directly inhibit the synthesis of pro-inflammatory cytokines such as IL-1 and TNF- $\alpha$ by human mononuclear cells, independently of eicosanoid regulation (Calder, 1997). Production of IL-2 by stimulated peripheral blood mononuclear cells is also decreased in human subjects supplemented with $n$-3 PUFA, with the suppression of IL-2 synthesis at the transcriptional level being one of the potential mechanisms involved (Calder, 1997).

The modulatory properties of $n-3$ PUFA on immune cell function, adhesion and eicosanoid and cytokine production have encouraged their therapeutic application in the treatment of a number of inflammatory diseases, including inflammatory bowel disease. Most of the effects reported earlier have been described for the systemic immune system. However, taking into account the therapeutic application of $n$-3 PUFA on inflammatory bowel disease it is reasonable to think that some of these effects and mechanisms are also applicable to the intestinal immune system, particularly in early life. In fact, Miura et al. (1998) have described that dietary fat is closely associated with immunological function of the intestinal mucosa, describing some of the mechanisms we have referred to here, and that is why careful manipulation of dietary fat can be important in management of inflammatory bowel disease. This is an interesting area for future research.

\section{Carbohydrates}

There are only a few studies reported about the specific effect of carbohydrates on the intestinal immune system. Most relate to the effect of different types of fibre, and almost all of them mention an interaction with the intestinal microbiota as the potential mechanism of action. In fact, one author has referred to this specific effect as eco-immunonutrition rather than immunonutrition (Bengmark, 1998). The specific effect of fibre on the intestinal immune system has been clearly demonstrated in experiments with rats fed on parenteral and enteral elemental diets. Both parenteral and enteral diets induce bacterial translocation and impair systemic and intestinal immune function. In these experiments fibre supplementation has been effective in reducing elemental diet-induced bacterial translocation and has significantly prevented diet-induced impairment of lymphocyte function (Xu et al. 1998). On the other hand, Kudoh et al. (1999) have described that IgA secretion from caecal mucosa is promoted by orally administered highly fermentable indigestible saccharides, while non- or low-fermentable indigestible saccharides reduced IgA responses in the intestinal tract. Recently, a positive effect of fructo-oligosaccharides on intestinal IgA in mice has also been reported (Manhart \& Roth, 2001).

Oligosaccharides also act as immunomodulators at the intestinal level. This action may derive from their role as prebiotics, which modify the intestinal microbiota (Gibson \& Roberfroid, 1994). Recent studies also suggest that breast-milk oligosaccharides might directly modulate the immune system. They have been found to inhibit neutrophil adhesion to stimulated vascular endothelial cells in a dose-dependent fashion (Klein et al. 2000). On the other hand, lacto-N-neotetraose, which is found in human milk, expands cells that secrete anti- 
inflammatory cytokines and inhibit proliferation of naive CD4(+) cells. These results suggest that human milk exhibits a ligand-specific mechanism involved in the generation of anti-inflammatory mediators that suppress Th1-type and inflammatory responses (Terrazas et al. 2001).

Within this context of prebiotics, it is important to mention the role of gangliosides. These compounds can be classified as lipids or carbohydrates, because both form part of their molecule. Gangliosides are glycosphingolipids consisting of a hydrophobic ceramide and a hydrophilic oligosaccharide chain bearing one or more sialic-acid residues in addition to a number of sugars, namely glucose, galactose, $\mathrm{N}$-acetylglucosamine and $\mathrm{N}$-acetylgalactosamine. Although gangliosides were first detected in the brain, it is possible to find them in almost all vertebrate tissues and body fluids (Rueda \& Gil, 1998).

Milk gangliosides are almost exclusively associated with the membrane fraction of the fat globule. Human and bovine milk have a different content and distribution of gangliosides (Rueda et al. 1995; Puente et al. 1996). Taking into account the potential role of human-milk gangliosides, the supplementation of infant formulae with these molecules could be influential in neonatal physiology.

The role of gangliosides in human milk has not been established. A high concentration of the disialoganglioside (GD) $\mathrm{GD}_{3}$ has been detected in developing tissues (Ando, 1983), as well as in human colostrum, and this latter fact may reflect a biological role in the development of organs such as the intestine in the neonate. Human milk also contains significant amounts of highly polar gangliosides (Rueda et al. 1995). It has been suggested that complex gangliosides in developing tissues act as mediators of specific types of cell-contact interactions during the early stages of mammalian development (Friedman et al. 1983). Thus, the complex gangliosides in human milk may play an important role in the mammary gland itself or in developing infant tissues, particularly the small intestine, during early life.

We have found that the addition of gangliosides to an adapted milk formula at a concentration similar to that in human milk modifies the microbial composition of faeces of preterm newborn infants. The faecal $E$. coli counts in preterm infants fed the ganglioside-supplemented formula was lower than that observed in infants fed the standard formula for the first month of life; conversely, the faecal counts of Bifidobacteria in the group receiving the ganglioside formula were higher, especially at $30 \mathrm{~d}$ of postnatal age (Rueda et al. 1998).

On the other hand, $\mathrm{GD}_{1 \alpha}$ and $\mathrm{GD}_{1}$ have been reported as differentiation markers for $\mathrm{Th} 2$ and Th1 lymphocyte subpopulations, respectively (Ebel et al. 1992). Different studies suggest that gangliosides could be involved in the activation of T cells (Yuasa et al. 1990) and in the differentiation of several lymphocyte subpopulations (Ebel et al. 1992; Nashar et al. 1996). As $\mathrm{GD}_{3}$ is one of the most important gangliosides in human milk, and has recently been shown to be implicated in the activation of T lymphocytes (Ortaldo et al. 1996), the supplementation of milk formulae with this ganglioside might contribute substantially to the process of proliferation, activation, and differentiation of intestinal immune cells in the neonate. Finally, it is important to point out that our group has recently reported that dietary gangliosides increase the number of intestinal IgA-secreting cells in mice at weaning (Vázquez et al. 1999) as well as the percentages of Th1 and Th2 cytokine-secreting cells in lamina propria and Peyer's patches, also from mice at weaning (Vázquez et al. 2001).

\section{Other compounds}

Within other compounds we will describe some reports related to the specific effect derived from several minerals, vitamins and phytochemicals. 
Minerals. Fe has traditionally been considered an important modulator of immunity. Two observations underlie the concept of nutritional immunity with regard to Fe. The first is the well-documented decrease in circulating Fe levels during acute infections, as Fe is rapidly taken up into tissue stores, and the second is the apparently heightened susceptibility to infection of patients with Fe overload syndromes, suggesting that excess Fe promotes infection. The ability of microorganisms to acquire $\mathrm{Fe}$ under adverse conditions of $\mathrm{Fe}$ availability, and the presence of low $\mathrm{Fe}$ levels as a signal to pathogens to make microbial virulence factors, raises serious questions as to how infection-mediated hypoferraemia affects immune function (Keusch, 1999).

$\mathrm{Fe}$ is required for the synthesis of DNA, which, in turn, is obligatory for the proliferation of lymphocytes involved in immune responses. Thus, Fe deficiency may lead to impaired lymphocyte proliferation. An Fe-dependent host defence mechanism, the neutrophil Fe metalloenzyme, myeloperoxidase, is clearly inhibited in Fe deficiency states (Keusch, 1999). On the other hand, Fe excess is associated with impaired immune function, including for example, diminished neutrophil superoxide and $\mathrm{H}_{2} \mathrm{O}_{2}$ production, diminished nitroblue tetrazolium reduction, and reduced bactericidal activity. These defects are probably due to the membranedamaging oxidative and peroxidative reactions associated with Fe excess (Keusch, 1999).

$\mathrm{Zn}$ is another mineral that has been implicated in the modulation of the immune response. The hypozincaemia of infection is part of the acute-phase response mediated by cytokines such as IL-1, which in this case induces the synthesis of the intracellular Zn-binding protein, metallothionine. The physiological role of this acute transfer of $\mathrm{Zn}$ from the extracellular space to the intracellular compartment is not clear but it may be related to the dependency of DNA transcription and RNA translation on Zn metallo-enzymes. Because of this, shifts of $\mathrm{Zn}$ to the intracellular compartment of lymphocytes could help increase the proliferative efficiency of lymphocytes involved in the immune response to infections and thus enhance host defence. $\mathrm{Zn}$ deficiency, on the other hand, might be expected to diminish the lymphocyte proliferative response and impair host defence (Keusch, 1999).

$\mathrm{Zn}$ also plays a role in regulating the activation of acute-phase genes via its ability to bind to RNA finger loop domains known as 'Zn fingers' involved in the conformational stabilization of transcription factor proteins that allow sequence-specific DNA recognition and gene expression. If $\mathrm{Zn}$ deficiency blocks these regulatory signals, host responses may be altered as the translation of genes normally activated during the acute-phase reaction is impaired. Another essential role of $\mathrm{Zn}$ in the immune response is its binding to certain thymus-derived peptides that appear to function as hormones in the differentiation of $\mathrm{T}$ cells, and whatever the mechanism, $\mathrm{Zn}$ deficiency leads to depression of delayed hypersensitivity responses. Furthermore, $\mathrm{Zn}$ status may affect the production and/or membrane binding of certain cytokine regulators of immune responses, including IL-1, IL-2 and interferon (Keusch, 1999).

Because of the recognized dependency of normal immune function on adequate $\mathrm{Zn}$ availability, the association of $\mathrm{Zn}$ deficiency with increased infective morbidity is explicable. Likewise, attention has recently turned to the possibility of using $\mathrm{Zn}$ supplements to reduce the incidence or severity of infection in malnourished children (Keusch, 1999). As for Fe, there are almost no reports about specific effects of $\mathrm{Zn}$ on the intestinal immune system. However, Darmon et al. (1997) have reported that $\mathrm{Zn}$ has anti-anaphylactic and anti-secretory properties that may contribute to its capacity to prevent intestinal dysfunction during malnutrition.

Se plays a part in the body's response to infection and contributes to the integrity of the immune system. In children with Down's syndrome, for instance, who are particularly prone to bacterial infection, Se supplementation has been shown to increase levels of serum IgG2. Se supplementation may also help to prevent age-related immunosuppression. Decreased immunocompetence in patients suffering from kwashiorkor may be related to low serum Se (Reilly, 
1999). It has been recently reported that in infections by nematodes the observed enhancement of immune responses, intestinal antibody and granulocyte numbers and in vitro worm-specific proliferation of lymphocytes, is associated with Mo intake (McClure et al. 1999).

$\mathrm{Cu}$ deficiency reduces antibody production, phagocytic activity, neutrophil respiratory burst, $\mathrm{T}$ cell proliferation and IL-2 production, increasing B-cell numbers. In addition, $\mathrm{Cu}$ is involved in complement function, cell membrane integrity, $\mathrm{Cu}-\mathrm{Zn}$ superoxide dismutase, and immunoglobulin structure (Kuvibidila et al. 1993; Myrvik, 1994).

Mg deficiency leads to higher thymic cellularity, eosinophils, IL-1, IL-6, TNF- $\alpha$, and histamine levels. Moreover, it is related to the production of acute-phase proteins and complement activity and influences cytotoxicity of lymphocytes through interactions with ATP and adhesion molecules (Kuvibidila et al. 1993; Myrvik, 1994).

Vitamins. Several vitamins have been related to immune response. Although animal studies have long shown a necessity for vitamin A in immune function, the molecular action of retinoids is still unknown. It also seems that some carotenoids function directly as modulators of immune function, and perhaps additionally as precursors of vitamin A (Furr, 1999). There is a report of the participation of vitamin $\mathrm{A}$ and its retinoid compounds in the modulation of the gut immune system (Elitsur et al. 1997). These authors have described that retinol suppressed and $c i s$-retinoic acid enhanced thymidine incorporation into lamina propria lymphocytes and concluded that retinol and retinoic acids (13-cis, all-trans) may alter the human colonic immune system possibly via IL-1 cytokine, but not via IL-6.

Vitamin E deficiency impairs immune responses, while supplementation with higher than recommended dietary levels enhances humoral and cell-mediated immunity and increases the efficiency of phagocytes. The vitamin $\mathrm{E}$ requirement for an optimal immune response appears to be several times higher than that needed to prevent vitamin E deficiency (Sheehy \& Morrissey, 1999). The mechanism of the immunostimulatory effect of vitamin $\mathrm{E}$ appears to be mainly related to its antioxidant function. Vitamin $\mathrm{E}$ could function either by decreasing concentrations of reactive oxygen species (for example, $\mathrm{H}_{2} \mathrm{O}_{2}$ ), thereby preventing oxidative damage to the stimulated immune and phagocytic cells, or by modulating production of arachidonic acid metabolites, such as PG (Sheehy \& Morrissey, 1999).

Phytochemicals. Research on phytochemicals and their impact on immune function has increased significantly during the past two decades as a result of encouraging epidemiological associations (Schmitz \& Chevaux, 2000). With regard to these phytochemicals, the carotenoids and flavonoids are two classes of compounds that illustrate how non-essential plant constituents may have an impact on human immune function and could potentially be useful for both the maintenance of optimal health and treatment of certain immunological disorders. However, the fundamental mechanisms by which some phytochemicals are able to impart immunomodulation in vitro and in vivo are largely speculative. Furthermore, there are no data about the influence of most of these substances on the immune response in children, despite relatively high intakes of these compounds.

\section{Nutrition and allergy}

The early exposure to food allergens may have a significant impact on subsequent development of allergies, which typically cause bloody stools and/or eczema in infancy. Food allergy is a 
significant health problem for 2-7\% of children aged less than 2 years old, with cows'-milk protein being the most common food allergen for infants (Cordle, 1994; Host et al. 1999; Exl, 2001). The relationship between breast-feeding and the development of atopy is controversial; although it may be true that dietary manipulation is only needed in individuals who are at high risk for developing atopy. Therefore, the identification of these individuals, by high cord blood $\mathrm{IgE}$, high serum IgE early in life and a significant family history of atopy might be important (Strimas \& Chi, 1988).

Duration of breast-feeding appears to have some influence on the prevalence of atopy. Studies on prolonged breast-feeding have shown prophylaxis against atopic disease up to 3 years of age or even to the age of 17 (Saarinen et al. 1979; Saarinen \& Kajosaari, 1995). Avoidance of cows'-milk-based formulae, and the use of an elimination diet during lactation have been shown to decrease atopy in infants at high risk (Arshad et al. 1992). Low concentrations of cows'-milk proteins can be detected in breast milk and maternal elimination of dairy products can reduce those levels significantly (Lilja et al. 1989). Although these findings suggest a protective effect of breast-feeding, results are inconsistent, mainly due to the multitude of confounders. More carefully controlled epidemiological studies are needed before definitive conclusions can be made regarding this topic (Lönnerdal, 2000).

The potential preventive effects of breast milk could be due to direct effects of breast milk in the intestinal tract or to indirect effects related to lifestyle of those who breast-feed predominantly. The inhibition of intestinal absorption of food antigens by secretory IgA and the maintenance of the natural protective barrier of intestinal mucosa to foreign substances carried by foods constitute the main direct effects (Chang \& Gershwin, 2000). On the other hand, the lower incidence of smoking in breast-feeding mothers is one of the indirect effects. Also, breast-fed infants are usually cared for at home and, thus, less frequently exposed to problems related to day-care settings. Breast-feeding may also lead to decreased or delayed exposure to other foods (Chang \& Gershwin, 2000).

The idea that breast-feeding, in contrast to cows'-milk-based formulae, prevents allergic disease has led to the manufacture of a great number of hypoallergenic formulae that minimize the native protein component of artificial formulae. From a compositional point of view, there are two main types of hypoallergenic formulae: those based on casein hydrolysates; those based on whey protein hydrolysates. Additionally, different protein hydrolysates can be distinguished based on the extent of hydrolysis. Some products, based on extensively hydrolysed milk proteins (50-55\% rate of hydrolysis), rarely have been associated with adverse reactions, although their main disadvantage is their bitter taste related to small size peptides. Products based on $12-15 \%$ rate of hydrolysis, with improved organoleptic properties, have been developed in order to enhance the development of oral tolerance to cows'-milk proteins. Currently, however, these milk protein partial hydrolysates are not considered safe for children at high risk of or suffering from cows'-milk-protein allergy (Businco et al. 1993; ESPGAN Committee on Nutrition, 1993; Ragno et al. 1993; Host et al. 1999).

Future directions of infant formula development include the use of biotechnology to produce formulae that can genetically exclude allergenic epitopes, and attempts to mimic the composition of breast milk as closely as possible in order to create a more hypoallergenic formula (Lönnerdal, 2000). However, there are other factors that also need to be taken into account. Age of introduction of solid foods has been proposed as an important factor in the induction of food allergy, although delayed introduction of a single allergen has been shown to postpone, but not prevent, the respective food allergy (Lönnerdal, 2000). A good strategy for decreasing atopy in infancy would include prolonged exclusive breast-feeding, maternal avoidance of milk, egg, peanut, and fish during lactation, and delayed introduction of solid foods for the first 6 months 
of life (Chang \& Gershwin, 2000). Likewise, there are a number of foods to avoid in high-risk atopic children, such as milk, egg, soya, peanut, fish, wheat and chicken (Chang \& Gershwin, 2000).

One of the recently studied mechanisms in the development of allergies and asthma concerns the role of oxygen free radicals. It has been postulated that in inflammatory diseases such as asthma, one of the pathological mechanisms includes the generation of free radicals by a variety of inflammatory cells, and the oxygen free radicals that cause oxidative damage to tissue. Whether or not antioxidant dietary supplements have a protective effect on development of allergies is not clear, but several minerals and vitamins with antioxidant protective effects, such as $\mathrm{Zn}, \mathrm{Se}, \mathrm{Mg}, \mathrm{Mn}$ and vitamins $\mathrm{C}$ and $\mathrm{E}$, could be used for this potential end (Chang \& Gershwin, 2000).

On the other hand, a diet with a high concentration of linoleic acid may induce increased quantities of arachidonic acid, which in turn may lead to increased production of leucotrienes in certain cell types. Taking into account the significance of leucotrienes in the asthmatic condition, there may be potential for dietary modification as a means to control asthma, although there is little evidence for this (Nagakura et al. 2000). The potential benefits of the use of fish oil with this end stem from its high concentration of eicosapentaenoic and docosahexaenoic acids. Eicosapentaenoic acid displaces arachidonic acid molecules in the oxidative metabolism of this class of PUFA. It is also interesting to note the relationship between the decrease in levels of arachidonic acid and di-homo- $\gamma$-linolenic acid at 1 and 3 months of life in the cord blood of formula-fed infants compared with breast-fed infants. The decrease was greater in those infants who subsequently developed atopic disease (Galli et al. 1994). These results contradict other studies that suggest that increasing the levels of arachidonic acid pathway substrates, such as linoleic acid, increases the incidence of atopic disease. This also constitutes another example of the controversy of results and of the need for more controlled studies before taking definitive conclusions.

Finally, some non-toxic adverse reactions to foods are immune-mediated. These reactions can affect several organs and may be IgE-mediated or non-IgE-mediated. Diagnosis of adverse food reactions is based on open food challenges, particularly with those believed to be culpable. Although food allergens are many, those of greater concern have been identified in cows' milk, egg, fish, soya, peanut, apple, celery and crustaceans. It is clear that the best treatment is the exclusion of food known to be responsible for an allergic response (Foschi et al. 2000).

\section{Probiotics and the immune system}

Western civilization is facing a progressive increase in immune-mediated, gut-related health problems, such as allergies and auto-immune and inflammatory diseases, and genetic factors are an unlikely explanation for this increase in disease incidence. Changes in hygiene and nutrition are two environmental factors most associated with modern lifestyle in developed countries. There has been a decline in the incidence of microbial stimulation by infectious diseases as a result of improved hygiene, vaccination and antimicrobial medication (Isolauri, 2001). Moreover, today the human diet contains several thousand times less bacteria than years ago, due to improved industrial and home processing and preservation of foods. As a result of changes in lifestyle, the component of our non-pathogenic bacterial environment, which is potentially beneficial to man, has changed significantly. The intestinal biota is important in the maintenance of the gut luminal milieu and in the mucosal integrity of intestinal epithelium, and nutrient metabolism and absorption (Saavedra, 2001). 
The increased use of functional foods by the public to improve their general health and prevent the incidence of chronic diseases has become a major area of interest within the nutrition community. Of the many functional foods available, probiotics have been best studied with regard to disease prevention, and most actively promoted in Europe, Japan and the USA. Probiotics are defined as live microbial food supplements that beneficially affect the host, either directly or indirectly, by improving its intestinal microbial balance. The alterations and improvements are mainly in the colon, which harbours a rich biota of more than 500 different species (10 14 organisms), with a variety of functions (Pathmakanthan et al. 2000).

The development of efficacious probiotics aims to provide microbial stimulus to the host immune system by means of beneficial living microbial cultures that are characteristic of the healthy human gut microbiota. Probiotic bacteria have been shown to reinforce the different lines of gut defence, which include immune exclusion, directed toward the exclusion of antigens, immune elimination of antigens that have penetrated the mucosa, and the regulation of ensuing antigen-specific immune responses (Isolauri, 2001).

Good probiotics should be: (a) capable of exerting a proven beneficial effect on the host, for example, resistance to disease; (b) non-pathogenic and non-toxic; (c) present as viable cells, preferably in large numbers; (d) capable of surviving in the gut (requiring resistance to acidic environments and organic acids and ability to maintain adhesiveness); (d) stable and capable of remaining viable for long periods under storage conditions. The most commonly used probiotics at present include Lactobacilli (Lactobacillus acidophilus, L. casei, L. rhamnosus strain GG ATCC 53103, L. bulgaricus, L. reuteri, L. plantarum) and Bifidobacteria (Bifidobacterium bifidum, B. longum, B. breve, B. infantis, B. animalis) (Pathmakanthan et al. 2000).

\section{Probiotics in infancy and childhood}

Several of the clinical applications that have been documented for the use of probiotic agents in infancy and childhood include facilitating digestion, alleviating the signs and symptoms of lactose intolerance, and prevention, treatment and significant improvement of atopic diseases (Saavedra, 2001) (Tables 3 and 4).

The best-established benefit of using probiotics has been in the management of paediatric diarrhoeal disease (Table 3). Several non-randomized trials have suggested a preventive effect of some fermented products on the risks of nosocomial and antibiotic-associated diarrhoea in children (Marteau et al. 2001). In addition, there is evidence from randomized, double-blind, placebo-controlled trials on effects of probiotics in the treatment and prevention of acute infectious diarrhoea in infants and children (Szajewska \& Mrukowicz, 2001).

Saavedra et al. (1994) have shown that feeding B. bifidum and S. thermophilus to infants admitted to the hospital significantly reduced the risk of diarrhoea and the shedding of rotavirus. L. rhamnosus GG (LGG) was found to be more effective than L. casei sp. rhamnosus or a combination of $S$. thermophilus and L. delbrïeckii sp. bulgaricus in promoting the immune response against rotavirus. Enhancement of IgA-specific antibody-secreting cells to rotavirus and serum IgA antibody levels at the convalescent stage was associated with LGG therapy (Majamaa et al. 1995). Likewise, intake of a formula supplemented with B. lactis, strain Bb-12, to children aged 15-31 months for $21 \mathrm{~d}$ resulted in significantly higher levels of total faecal IgA and anti-polio virus IgA than before intake of the probiotics (Fukushima et al. 1998). LGG also proved effective in the prevention of acute diarrhoea in undernourished Peruvian children. Thus, LGG may be useful as a prophylactic measure to control diarrhoea in children at increased risk, especially non-breast-fed children in the toddler age group (Oberhelman et al. 1999). 
LGG has been shown to be effective not only at preventing but also at reducing the duration of diarrhoea by about half in several randomized, placebo-controlled trials (Isolauri, 2001; Marteau et al. 2001; Saavedra, 2001). Guandalini et al. (2000) have reported that administering oral rehydration solution containing LGG to children with acute diarrhoea is safe and results in shorter duration of diarrhoea, less chance of a protracted course, and faster discharge from hospital. LGG also proved effective in the treatment of acute diarrhoea in Asia (Raza et al. 1995). The results of one study suggested that heat-inactivated LGG was as effective as living LGG in reducing the duration of diarrhoea; however, the effect of the living probiotics was more pronounced on rotavirus-specific IgA response (Kaila et al. 1995). Enterococcus faecium SF 68 was also shown to shorten the duration of diarrhoea in two randomized trials in infants, and other probiotics may be effective (Marteau et al. 2001).

The use of antibiotics constitutes an assault on GI biota and is accepted as one of the risks taken when treating severe infections. Diarrhoea occurs in about $20 \%$ of patients who receive antibiotics; $C$. difficile and Klebsiella oxytoca contribute to the occurrence of antibiotic-associated diarrhoea. Probiotics would be a reasonable alternative to help the GI microbiota resist the overgrowth of potentially pathogenic bacteria. LGG has been shown to reduce the incidence of antibiotic-associated diarrhoea in children treated with oral antibiotics for common childhood infections, such as respiratory infections (Arvola et al. 1999). Saccharomyces boulardii has also been reported to reduce the duration of antibiotic-associated diarrhoea. The mechanism involved with $S$. boulardii is unclear because multiple effects of yeasts in the GI tract have been shown, including effects against $C$. difficile populations, toxin levels, and intestinal secretion (Marteau et al. 2001).

The traditional approach to food hypersensitivity, of which atopic disease is a manifestation, has been the elimination of potential protein offenders in the diet. Intestinal microbiota can contribute to the processing of food antigens in the gut, and probiotics could modify the structure of potential antigens and reduce their immunogenicity. Moreover, gut microbiota contribute to the generation of a Th population amenable to oral tolerance induction. This offers a new therapeutic approach to the management of hypersensitive disorders (Saavedra, 2001). A recent randomized placebo-controlled trial has shown that LGG, when given prenatally to mothers who had at least one first-degree relative with atopic eczema, allergic rhinitis, or asthma, and postnatally to their infants for 6 months, prevents early atopic disease (Kalliömaki et al. 2001). If confirmed in other studies and applicable to other allergic diseases, probiotics could represent an important therapeutic advance. Table 4 summarizes the effect of probiotics on different aspects of immunity.

\section{Mechanism of action of probiotics}

The mechanisms by which probiotics affect the immune system are mostly unknown. Probiotics can protect the intestine by competing with pathogens for attachment, strengthening tight junctions between enterocytes, and enhancing the mucosal immune response to pathogens (Lu \& Walker, 2001); bacterial cell wall components and bacterial DNA may also be involved (Hanson et al. 1999). Intestinal colonization is accompanied by an increase in the numbers of intestinal lymphocytes and maturation of mucosal immune function, and intraluminal bacteria antigens elicit specific responses in gut-associated lymphoid tissue.

Activation of the intestinal epithelial lymphocytes by bacteria or bacterial products can lead to modifications of the intestinal epithelial cell phenotype. It was demonstrated that $\gamma$-interferon derived from activated intra-epithelial lymphocytes can induce the expression of 


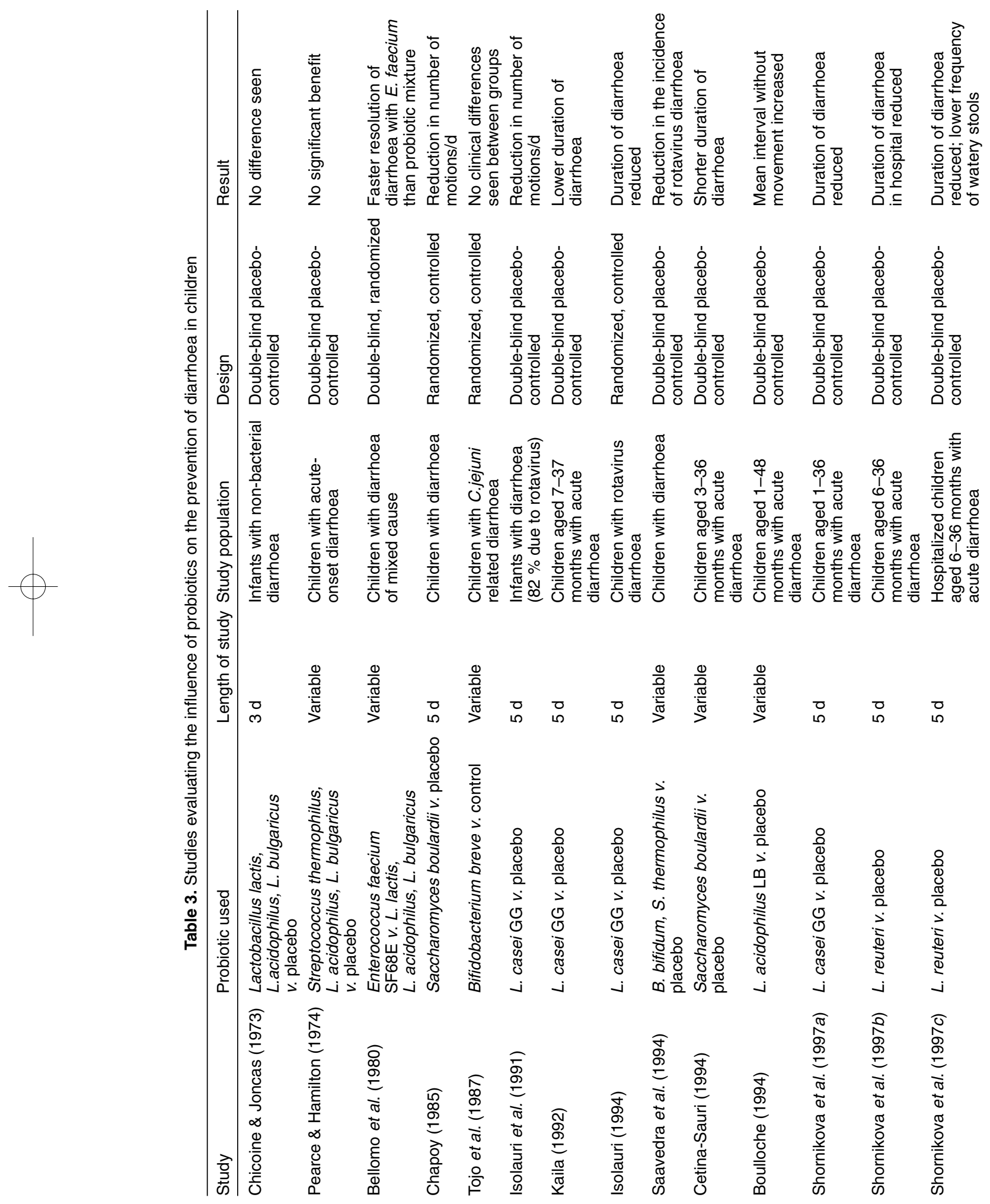




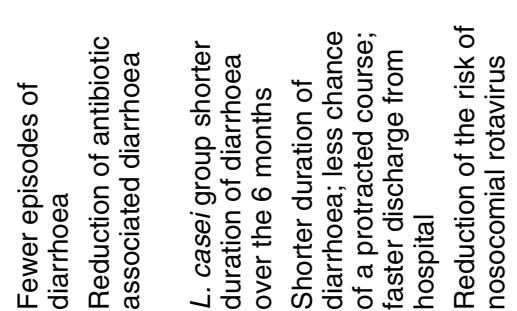

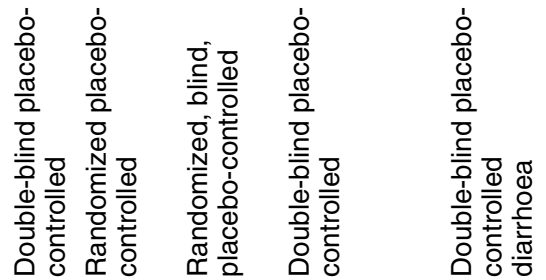

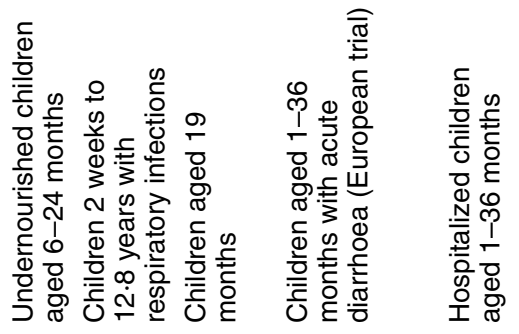
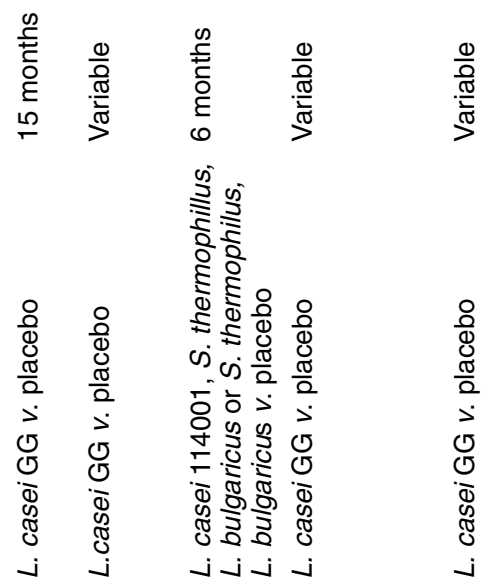

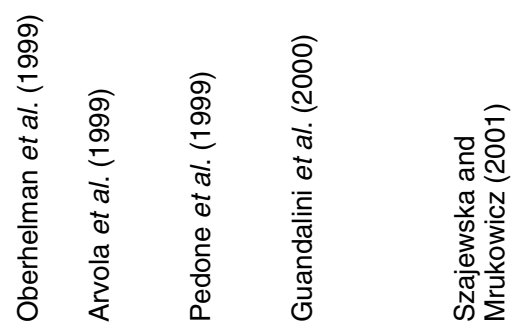

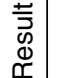

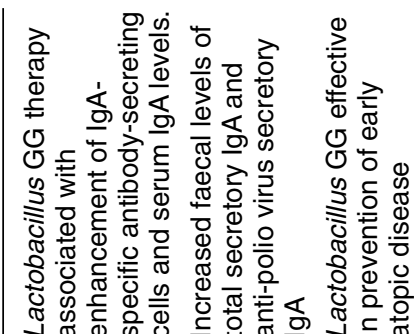

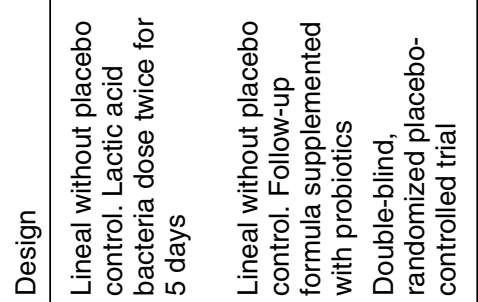

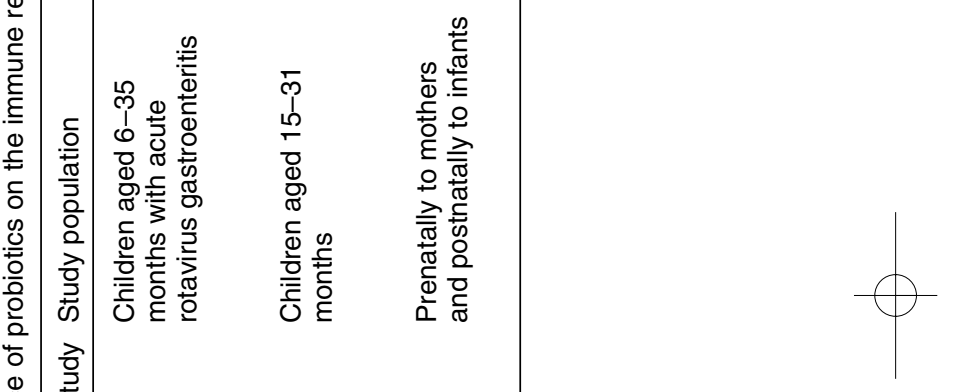


immune markers such as major histocompatibility class II on intestinal epithelial cells. Moreover, the lack of major histocompatibility class II expression during the neonatal period or in germ-free animals strongly suggests a role for the normal microbiota in the immune regulation at the epithelial compartment (Blum et al. 2000).

Lactic acid bacteria alone or in combination with $\gamma$-interferon, in contrast to pathogenic bacteria, does not show any agonistic effect with regard to the onset of pro-inflammatory cytokines, which suggests that probiotics could participate in tissue protection against the deleterious effect of an ongoing inflammatory process.

Experimental evidence clearly shows that the indigenous bacterial biota is the primary stimulus for the development of IgA-secreting plasma cells. The capacity to generate IgA-producing cells is initiated with the establishment of the gut microbiota, but drops with the onset of a specific IgA response to a number of translocating bacteria, reflecting the maturation of the immunological defence mechanisms of the intestine. Moreover, there is a reduction in the number of lamina propria lymphocytes and the concentration of serum immunoglobulin. In addition, the spleen and lymph nodes of germ-free animals are poorly developed because of the lack of antigen stimulation. In these animals, the production of IgE antibodies, after oral administration of ovalbumin, is maintained until they are colonized by intestinal microbiota at the neonatal stage, but not later. These results suggest that the gut microbiota direct the regulation of systemic and local immune responsiveness by affecting the development of gut-associated lymphoid tissue at an early age (Sudo et al. 1997). Similar results have been obtained in infants born by Caesarean delivery in which colonization was associated with the maturation of humoral immune mechanisms, particularly of circulating IgA- and IgM-secreting cells (Grönlund et al. 2000). Furthermore, lymphoid aggregates from germ-free animals are devoid of germinal centres and the development of this B-cell compartment depends on a specific immune response against colonizing bacteria (Blum et al. 2000).

The GI epithelium is covered by a protective mucus gel synthesized and secreted by goblet cells. Changes in goblet cell function and in the chemical composition of intestinal mucus are detected in response to a broad range of luminal insults, including alterations of the normal microbiota. Available data indicate that intestinal microbes may affect goblet cell dynamics, and the mucus layer directly, via the local release of bioactive factors or indirectly via activation of host immune cells (Deplancke \& Gaskins, 2001).

The exact mechanisms by which probiotics may affect atopic disease remain speculative. However, there is increasing evidence that specific input from the faecal microbiota to the innate immune system is essential for the establishment and maintenance of the mucosal immune system (Aderen \& Ulevitch, 2000; Murch, 2000). High-mannose-containing carbohydrates from bacteria interact with the mannose receptor of dendritic cells and macrophages targeting to endosomal compartments with increased efficiency of antigen presentation. Likewise, bacterial surface glycan epitopes are recognized by antibodies secreted by peritoneal and intestinal B-1 cells, distributed in the lamina propria and the epithelial compartment, leading to $\mathrm{T}$ cell activation in concert with complement. Moreover, a broad spectrum of bacterial O- and $\mathrm{N}$-linked glycans may be recognized by complement components and co-localize with natural antibodies resulting in opsonization and regulation of $\mathrm{T}$ cell activation and $\mathrm{B}$ cell tolerance by negative selection. In particular, the toll-like receptor (TLR) proteins TLR2, TLR4, and TLR9, expressed on both enterocytes and immune cells, recognize bacterial TLR2-peptidoglycans, TLR4 lipopolysaccharide and TLR9-unmethylated cytidine phosphate guanosine, respectively, and induce production of Th1 cytokines through a process dependent on nuclear factor- $\mathrm{k}$ (Aderen \& Ulevitch, 2000). 
It is likely that some of the beneficial effects of probiotic bacteria in allergic disease rest with the ability of these organisms to alter mucosal permeability. However, it is also possible that intestinal bacteria can direct the intestinal immune system to a Th1 or Th2 response. LGG and some streptococci have been reported to activate nuclear factor-кB and STAT signalling pathways in human macrophages (Newberry et al. 1999). This effect could only explain decreased Th2-mediated allergy. However, specific immunological unresponsiveness to dietary components (oral tolerance) and to commensal bacteria is critically dependent on the inhibition of potential lymphocyte reactivity, and two recently recognized suppressor-cell populations are central to this process (Murch, 2001). Th3 and T regulator 1 cells, which produce TGF- $\beta$ and IL-10, respectively, have been shown in murine models to down regulate mucosal inflammatory responses through 'bystander suppression' of nearby lymphocytes of various specificities; deficiency of either cytokine or cell type leads to mucosal inflammation as a consequence of unchecked response to enteric microbiota (Murch, 2000). A study in transgenic mice with a single lymphocyte population specific for dietary antigen suggests that the role of Lactococcus lactis in the generation of regulatory lymphocytes leads to oral tolerance, through the induction of macrophage $\mathrm{PGE}_{2}$ production, via IL-10 and TGF- $\beta$ (Steidler et al. 2000). These results suggest that the massive changes in initial gut colonization during the past century may be responsible for the rise in the prevalence of allergy (Murch, 2001). However, it should be emphasized that the gut immune system in man may differ greatly from that in mice with regard to the immune response of dietary components. This intrinsic difference should be taken into account and the potential of probiotics to modify intestinal immune responses in man should be put forward more cautiously. This area is of enormous scientific interest and needs further research.

The adhesion of the faecal bifidobacteria from healthy infants, characterized by high levels of $B$. bifidum, is significantly higher than for allergic infants, whose gut flora are composed of high levels of $B$. adolescentis. This suggests a correlation between allergic disease and the presence of intestinal microbiota, with reduced ability to adhere to the intestinal mucus (He et al. 2001).

In addition to the effects of LGG to reduce a number of indicators of inflammation in allergic disease, LGG and L. plantarum $299 \mathrm{v}$ appear to be able to reduce the translocation of both bacteria and antigens. The effects of probiotics on inflammatory diseases have been shown most elegantly in animal models, particularly in rats after administration of methotrexate. In the rat model probiotics reduce bacterial translocation and enhance mucosal regeneration. Likewise, in patients with small bowel bacterial overgrowth, the administration of both LGG and L. plantarum $299 \mathrm{v}$ results in significant improvement of the disease, as well as in nutritional parameters (Vanderhoof, 2000). Similarly, an infant with short bowel syndrome treated with L. casei Shirota improved dramatically in terms of Na balance, as well as the symptoms of the disease, with a reduction in diarrhoea episodes (Candy et al. 2001).

There are theoretical reasons why probiotics might be effective in the treatment of inflammatory diseases such as Crohn's disease, ulcerative colitis and necrotizing enterocolitis. However, the usefulness of probiotics in older children with inflammatory diseases should be studied in a controlled fashion. Normally, the intestinal immune system appears to be tolerant to autologous biota; however, this tolerance is lost in patients with Crohn's disease. L. plantarum 299v has been shown to be beneficial in improving inflammatory lesions in an IL-10 knockout mouse model of Crohn's disease (Veltkamp et al. 1999). It is likely that lactic acid bacteria could result in reduction of inflammation by preventing the overgrowth of potentially pathogenic bacteria, as well as by maintaining the integrity of the gut barrier. 


\section{Conclusion}

Nutrients act as critical factors in the regulation of the immune responses, particularly in early life. In addition, GI microbiota modulate the immune response, stimulating the production of growth factors, cytokines and regulatory molecules, which selectively control regional immune function. Moreover, some micro-organisms, such as lactic acid bacteria, directly promote the development of the mucosal barrier by stimulation of the immune response.

Human milk contains a number of factors, including immunocytes, secretory IgA, lactoferrin, lysozyme, casein peptides, growth factors, cytokines, polyamines, nucleotides, complex oligosaccharides, gangliosides, long-chain PUFA, and other minor components, which directly affect the responsiveness and activity of the immune system of the infant. All these immunomodulatory agents help to boost the infant's immune system that has not been fully developed and aid in the proper response against challenges to the system. Breast-feeding also appears to have some influence on the prevalence of atopy. The preventive effects of breast milk may be due to direct effects of their components in the intestinal tract or to indirect effects related to the lifestyles of those who breast-feed predominantly.

Western countries are facing a progressive increase in immune-mediated, gut-related health problems, such as allergies, and auto-immune and inflammatory diseases. Improved hygiene, vaccination, anti-microbial medication, and the use of preserved foods have resulted in a lower incidence of microbial stimulation. In addition, as a result of changes in lifestyle, the component of our non-pathogenic bacterial environment has changed significantly. The consumption of probiotics aims to provide microbial stimulus to the host immune system. Probiotic bacteria have been shown to reinforce the gut defence, particularly in infancy and childhood. A number of probiotics, such as LGG, have been documented to be useful in the prevention and treatment of acute diarrhoea, as well as in the improvement of atopic diseases in children. Intestinal colonization is accompanied by an increase in the numbers of intestinal lymphocytes and maturation of mucosal immune function. However, the molecular mechanisms by which probiotics affect the immune system remain mostly unknown; further research in this area is needed.

\section{References}

Adamik B \& Wlaszczyk A (1996) Lactoferrin - its role in defense against infection and immunotropic properties. Postepy Higieny Medycyny Doswiadczalnej 50,33-41.

Aderen A \& Ulevitch RJ (2000) Toll-like receptors in the induction of the innate immune response. Nature 408 , $740-745$.

Andersson B, Porras O, Hanson LA, Lagergard T \& Svanborg-Eden C (1986) Inhibition of attachment of Streptococcus pneumoniae and Haemophilus influenzae by human milk and receptor oligosaccharides. Journal of Infectious Diseases 153, 232-237.

Ando S (1983) Gangliosides in the nervous system. Neurochemistry International 5, 507-537.

Arshad SH, Matthews S, Gant C \& Hide DW (1992) Effect of allergen avoidance on development of allergic disorders in infancy. Lancet 339, 1493-1497.

Arvola T, Laiho K, Torkkeli S, Mykkänen H, Salminen S, Maunula L \& Isolauri E (1999) Prophylactic Lactobacillus GG reduces antibiotic-associated diarrhea in children with respiratory infections: A randomized study. Pediatrics 104, 64-67.

Bellomo G, Mangiagle A, Nicastro L \& Frigerio G (1980) A controlled double-blind study of SF68 strain as a new biological preparation for the treatment of diarrhoea in paediatrics. Current Therapy Research 28, 927-936.

Bengmark S (1998) Immunonutrition: role of biosurfactants, fiber, and probiotic bacteria. Nutrition 14, 585-594.

Bland PW \& Warren LG (1986) Antigen presentation by epithelial cells of rat small intestine. I. Kinetics, antigen specificity and blocking by anti-Ia antisera. Immunology 58, 1-8.

Blum S, Delneste Y, Donnet A \& Schiffrin EJ (2000) The influence of probiotic organisms on the immune response. In Nutrition and Immunology: Principles and Practice, pp. 451-455 [ME Gershwin, JB German and CL Keen, editors]. NJ: Humana Press, Inc. 
Boulloche J, Mouterde O \& Mallet E (1994) Management of acute diarrhoea in infants and young children. Controlled study of the anti-diarrhoeal efficacy of killed L. acidophilus (LB strain) versus a placebo and a reference drug (Loperamide). Annales de Pediatrie 41, 1-7.

Brandtzaeg P \& Nilssen DE (1995) Mucosal aspects of primary B-cell deficiency and gastrointestinal infections. Current Opinion in Gastroenterology 11, 532-540.

Brunser O, Espinoza J, Araya M, Cruchet S \& Gil A (1994) Effect of dietary nucleotide supplementation on diarrhoeal disease in infants. Acta Paediatrica 83, 188-191.

Buck RH, Thomas DL, Winship TR, Cordle CT, Schaller JP, Kuchan MJ, Baggs GE \& Wheeler JG (2001) Dietary nucleotides enhance immune cell maturation in infants. Journal of Pediatric Gastroenterology and Nutrition 33, 393.

Buescher ES \& Malinowska I (1996) Soluble receptors and cytokine antagonists in human milk. Pediatric Research 40 , 839-844.

Businco L, Dreborg S, Einarsson R, Giampietro PG, Host A, Keller KM, Strobel S \& Wahn U (in cooperation with Björksten B, Kjellman MN-I, Sampson H \& Zeiger R) (1993) Hydrolysed cow's milk formulae. Allergenicity and use in treatment and prevention. An ESPACI position paper. Pediatric Allergy and Immunology 4, 101-111.

Calder PC (1997) N-3 polyunsaturated fatty acids and immune cell function. Advances in Enzyme Regulation 37, $197-237$.

Campbell DA, Lorber MI, Sweeten JC, Turcoite JC, Niederhuber J \& Beer AE (1984) Breast-feeding and maternaldonor renal allografts. Transplantation 37, 340-344.

Candy DCA, Densham L, Lamont LS, Greig M, Lewis J, Bennet H \& Griffiths M (2001) Effect of administration of Lactobacillus casei Shirota on sodium balance in an infant with short bowel syndrome. Journal of Pediatric Gastroenterology and Nutrition 32, 506-508.

Cervantes LE, Newburg DS \& Ruiz-Palacios GM (1995) $\alpha-1-2$ Fucosylated chains (H-2 and Lewis $\left.{ }^{b}\right)$ are the human milk receptor analogs for Campylobacter. Pediatric Research 37, 171A.

Cetina-Sauri G \& Sierra-Basto G (1994) Evaluation therapeutique de Saccharomyces boulardii chez les enfants souffrant de diarrhée aigue (Therapeutical evaluation of Saccharomyces boulardii in infants suffering acute diarrhoea). Annales de Pediatrie 41, 397-400.

Chang C \& Gershwin E (2000) Nutrition and allergy. In Nutrition and Immunology, pp. 221-231 [ME Gershwin, JB German and CL Keen, editors]. Totowa, NJ: Humana Press.

Chapoy P (1985) Traitement des diarrhees aigues infantiles: Essai contrôlé de Saccharomyces boulardii (Treatment of infantile acute diarrhoea: Controlled assay with Saccharomyces boulardii). Annales de Pediatrie 32, 561-563.

Chicoine L \& Joncas JH (1973) Emploi des ferments lactiques dans la gastro-enterite non bactérienne (Use of lactic starters in non-bacterial gastroenteritis). Union Medical Canadien 102, 1114-1115.

Coop RL \& Holmes PH (1996) Nutrition and parasite interaction. International Journal of Parasitology 26, $951-962$.

Cordle CT (1994) Control of food allergies using protein hydrolysates. Food Technology Oct, 72-76.

Corridan B \& Wilson A (1999) Fatty acids - Health effects of n-3 polyunsaturated fatty acids. In Encyclopedia of Human Nutrition, pp. 759-769 [MJ Sadler, JJ Strain and B Caballero, editors]. London: Academic Press.

Cravioto A, Tello O, Villafari H, Ruiz J, del Vedobo S \& Neeser J-R (1991) Inhibition of localized adhesion of localized enteropathogenic Escherichia coli to Hep-2 cells by immunoglobulin and oligosaccharide fractions of human colostrum and breast milk. Journal of Infectious Diseases 163, 1247-1255.

Cripps AW \& Gleeson M (1999) Ontogeny of mucosal immunology and aging. In Mucosal Immunology, 2nd ed., pp. 253-266 [PL Ogra, J Mestecky, ME Lamm, W Strober, J Bienenstock and JR McGhee, editors]. San Diego, CA: Academic Press.

Cummins AG \& Thompson FM (1997) Postnatal changes in mucosal immune response: a physiological perspective of breast feeding and weaning. Immunology and Cell Biology 75, 419-429.

Cunningham-Rundles S \& Lin DH (1998) Nutrition and the immune system of the gut. Nutrition 14, 573-579.

Darmon N, Pelissier MA, Candalh C, Chappuis P, Blaton MA, Albrecht R, Desjeux JF \& Heyman M (1997) Zinc and intestinal anaphylasis to cow's milk proteins in malnourished guinea pigs. Pediatric Research 42, 208-213.

Davis MK, Savitz DA \& Grauford B (1988) Infant feeding in childhood. Lancet ii, 365-368.

Debbabi H, Dubarry M, Rautureau M \& Tome D (1998) Bovine lactoferrin induces both mucosal and systemic immune response in mice. Journal of Dairy Research 65, 283-293.

Deplancke B \& Gaskins RH (2001) Microbial modulation of innate defense: goblet cells and the intestinal mucus layer American Journal of Clinical Nutrition 73, Suppl., 1131S-1141S.

Dosch HM, Martin JM, Bobinson BH, Akerblom HK \& Karjalainen J (1993) An immune basis for disproportionate diabetes risks in children with a type I diabetic mother or father. Diabetes Care 16,949-951.

Ebel F, Schmitt E, Peter-Katalinic J, Kniep B \& Mühlradt PF (1992) Gangliosides: Differentiation Markers for Murine T Helper Lymphocyte Subpopulations TH1 and TH2. Biochemistry 31, 12190-12197.

Elitsur Y, Neace C, Liu X, Dosescu J \& Moshier JA (1997) Vitamin A and retinoic acids immunomodulation on human gut lymphocytes. Immunopharmacology 35, 247-253.

Elmer GW, Surawicz CM \& McFarland L (1996) Biotherapeutic agents, a neglected modality for the treatment and prevention of selected intestinal and vaginal infections. JAMA 275, 870-876.

ESPGAN Committee on Nutrition: Aggett PJ, Haschke F, Heine W et al. (1993) Comment on antigen-reduced infant formulae. Acta Paediatrica 82, 314-319.

Evoy D, Lieberman MD, Fahey TJ III \& Daly JM (1998) Immunonutrition: role of arginine. Nutrition 14, 611-617.

Exl BM (2001) A review of recent developments in the use of moderately hydrolyzed whey formulae in infant nutrition. Nutrition Research 21, 355-379. 
Field CJ, Clandinin MT \& Van Aerde JE (2001) Polyunsaturated fatty acids and T-cell function: implications for the neonate. Lipids 36, 1025-1032.

Foschi FG, Marsigli L, Chiappelli F, Kung MA, Bernardi M \& Stefanini GF (2000) Adverse reactions to foods. In Nutrition and Immunology, pp. 233-246 [ME Gershwin, JB German and CL Keen, editors]. Totowa, NJ: Humana Press.

Friedman SJ, Cheng S \& Skehan P (1983) The occurrence of polysialogangliosides in a human trophoblast cell line. FEBS Letters 152, 175-179.

Fukushima Y, Kawata Y, Hara H, Terada A \& Mitsuoka T (1998) Effect of a probiotic formula on intestinal immunoglobulin A production in healthy children. International Journal of Food Microbiology 42, 39-44.

Furr HC (1999) Retinol - Physiology. In Encyclopedia of Human Nutrition, pp. 1708-1713 [MJ Sadler, JJ Strain and B Caballero, editors]. London: Academic Press.

Galli E, Picardo M, Chini L, Passi S, Moscheve V, Terminalli O, Paone F, Fraioli G \& Rossi P (1994) Analysis of polyunsaturated fatty acids in newborn sera: a screening tool for atopic disease. British Journal of Dermatology 130 , $752-756$.

Gibson GR \& Roberfroid MB (1994) Dietary modulation of human colonic microbiota, introducing the concept of prebiotics. Journal of Nutrition 125, 1401-1412.

Gil A (2002) New additions to infant formulas. In Pediatric Gastroenterology and Nutrition in Clinical Practice, pp. 113-135 [CH Lifschitz, editor]. New York: Marcel Dekker.

Gil A, Corral E, Martínez A \& Molina JA (1986) Effects of the addition of nucleotides to an adapted milk formula on the microbial patterns of faeces in at term newborn infants. Journal of Clinical Nutrition and Gastroenterology 1, $127-132$.

Goldman AS (1993) The immune system of human milk: antimicrobial, anti-inflammatory, and immunomodulating properties. Pediatric Infectious Disease Journal 12, 664-672.

Goldman AS, Garza C, Johnson CA, Nichols BL \& Goldblum RM (1982) Immunologic factors in human milk during the first year of lactation. Journal of Pediatrics 100, 563-567.

Grönlund MM, Arvilommi H, Kero P, Lehtonen OP \& Isolauri E (2000) Importance of intestinal colonisation in the maturation of humoral immunity in early infancy: a prospective follow up study of healthy infants aged 0-6 months. Archives of Disease in Childhood 83, F186-F192.

Guandalini S, Pensabene L, Zikri MA et al. (2000) Lactobacillus GG administered in oral rehydration solution to children with acute diarrhea: A multicenter European trial. Journal of Pediatrics in Gastroenterology and Nutrition 30, 54-60.

Hahn-Zoric M, Fulconis F, Minoli I, Moro C, Carlsson B, Böttigen M, Räqhä N \& Hanson LA (1990) Antibody responses to parenteral and oral vaccines are impaired by conventional and low protein formulas as compared to breastfeeding. Acta Paediatrica Scandinavica 79, 1137-1142.

Hanson LA, Dahlman-Höglund A, Karlsson M, Lundin S, Dahlgren U \& Telemo E (1999) Normal microbial flora of the gut and the immune system. In Probiotics, Other Nutritional Factors and Intestinal Microflora, Nestlé Nutrition Workshop series no. 42, pp. 217-228 [LA Hanson and RH Yolken, editors]. Philadelphia: Nestec Ltd, Vevey/Lippincot-Raven Publishers.

Hanson LA, Telemo E, Wiedermann U, Dahlman-Höglund A, Lundin S, Friman V \& Dahlgren U (1995) Immunological mechanisms of the gut. Pediatric Allergy and Immunology 6, 7-12.

He F, Ouweland AC, Isolauri E, Hashimoto H, Benno Y \& Salminen S (2001) Comparison of mucosal adhesion and species identification of bifidobacteria isolated from healthy and allergic infants. FEMS Immunology and Medical Microbiology 30, 43-47.

Holmgren J, Svennerholm AM \& Lindblad M (1983) Receptor-like glycocompounds in human milk that inhibit classical and El Tor Vibrio cholerae cell adherence (hemagglutination). Infection and Immunity 39, 147-154.

Host A, Koletzko B, Dreborg S, Muraro A, Wahn U, Aggett PJ, Bresson JL, Hernell O, Lafeber H, Michaelsen KF, Micheli JL, Rigo J, Weaver L, Heymans H, Strobel S \& Vandenplas Y (1999) Joint statement of ESPACI and ESPGHAN. Dietary products used in infants for treatment and prevention of food allergy. Archives of Disease in Childhood 81, 80-84.

Hughes DA \& Pinder AC (1997) N-3 polyunsaturated fatty acids modulate the expression of functionally associated molecules on human monocytes and inhibit antigen-presentation in vitro. Clinical and Experimental Immunology 110, 516-523.

Hughes DA \& Pinder AC (2000) n-3 polyunsaturated fatty acids inhibit the antigen-presenting function of human monocytes. American Journal of Clinical Nutrition 71, 357S-360S.

Isolauri E (2001) Probiotics in human disease. American Journal of Clinical Nutrition 73, Suppl., 1142S-1146S.

Isolauri E, Juntunen M, Rautanen T, Sillanaukee P, Koivula T (1991) A human Lactobacillus strain (Lactobacillus casei sp GG) promotes recovery from acute diarrhoea in children. Pediatrics 88, 90-97.

Isolauri E, Kaila M, Mykkanen H, Ling WH \& Salminen S (1994) Oral bacteriotherapy for viral gastroenteritis. Digestive Disease Sciences 39, 2595-2600.

Isolauri E, Majamaa H, Arvola T, Rantala I, Virtanen E \& Arvilommi H (1993) Lactobacillus casei strain GG reverses increased intestinal permeability induced by cow milk in suckling rats. Gastroenterology 105, 1643-1650.

Jyonouchi H, Sun S \& Sato S (1996) Nucleotide-free diet suppresses antigen-driven cytokine production by primed T cells: effects of supplemental nucleotides and dietary fatty acids. Nutrition 12, 608-615.

Jyonouchi H, Sun S, Winship T \& Kuchan MJ (2001) Dietary ribonucleotides modulate type 1 and type 2 T-helper cell responses against ovalbumin in young BALB/cJ mice. Journal of Nutrition 131, 1165-1170. 
Jyonouchi H, Zhang-Shanbhag L, Tomita Y \& Yokoyama H (1994) Nucleotide-free diet impairs T-helper cell functions in antibody production in response to T-dependent antigens in normal C57B1/6 mice. Journal of Nutrition 124, 475-484.

Kagnoff MF (1993) Immunology of the intestinal tract. Gastroenterology 105, 1275-1280.

Kaila M, Isolauri E, Saxelin M, Arvilommi H \& Vesikalari T (1995) Viable versus inactivated Lactobacillus strain GG in acute rotavirus diarrhoea. Archives of Disease in Childhood 72, 51-53.

Kaila M, Isolauri E, Soppi E, Virtanen E, Laine S \& Arvilommi H (1992) Enhancement of the circulating antibody secreting cell response in human diarrhoea by a human Lactobacillus strain. Pediatric Research 32, 141-144.

Kakai R, Bwayo JJ, Wamola IA, Ndinya-Achola JO, Nagelkerke NJ, Anzala AO \& Plummer FA (1995) Breastfeeding and immunity to intestinal infections. East African Medical Journal 72, 150-154.

Kalliömaki M, Salminen S, Arvilommi H, Kero P, Koskinen P \& Isolauri E (2001) Probiotics in primary prevention of atopic disease: a randomized placebo-controlled trial. Lancet 357, 1076-1079.

Keeney SE, Schmalstieg FC, Palkowetz KH, Rudloff HE, Le BM \& Goldman AS (1993) Activated neutrophils and neutrophil activators in human milk. Increased expression of CD11b and decreased expression of L-selectin. Journal of Leukocyte Biology 54, 97.

Keusch GT (1999) Immunity - Role of iron and zinc. In Encyclopedia of Human Nutrition, pp. 1081-1085 [MJ Sadler, JJ Strain and B Caballero, editors]. London: Academic Press.

Klein N, Schwertmann A, Peters M, Kunz C \& Strobel S (2000) Immunomodulatory effects of breast milk oligosaccharides. Advances in Experimental Medicine and Biology 478, 251-259.

Kolb H \& Pozzilli P (1999) Cow's milk and type I diabetes: the gut immune system deserves attention. Immunology Today 20, 108-110.

Koletzko S, Sherman P, Corem M, Griffiths A \& Smith C (1989) Role of infant feeding practices in Crohn's disease in childhood. British Medical Journal 298, 1617-1618.

Korhonen TK, Valtonen MV, Parkkinen J, Väisänen-Rhen V, Finne J \& Orskov I (1985) Serotypes, hemolysin production and receptor recognition of Escherichia coli strains associated with neonatal sepsis and meningitis. Infection and Immunity 48, 486-491.

Kudoh K, Shimizu J, Ishiyama A, Wada M, Takita T, Kanke Y \& Innami S (1999) Secretion and excretion of immunoglobulin A to cecum and feces differ with type of indigestible saccharides. Journal of Nutritional Science and Vitaminology 45, 173-181.

Kunz C \& Rudolff S (1993) Biological functions of oligosaccharides in human milk. Acta Paediatrica 82, 902-912.

Kuvibidila S, Lolie Y, Ode D \& Warrier RP (1993) The immune response in protein-energy malnutrition and single nutrient deficiencies. In Human Nutrition, a Comprehensive Treatise, pp. 121-155 [DM Klurfeld, editor]. New York: Plenum.

Lama RA \& Gil-Alberdi B (1998) Efecto de la supplementación dietética con nucleótidos sobre la diarrea en el lactante sano (Effect of nucleotide dietary supplementation on diarrhoea in healthy infants). Anales Españoles de Pediatría 48, 371-375.

Li J, King BK, Janu PG, Renegar KB \& Kudsk KA (1998) Glycyl-L-glutamine enriched total parenteral nutrition maintains small intestine gut-associated lymphoid tissue and upper respiratory tract immunity. Journal of Parenteral and Enteral Nutrition 22, 31-36.

Lilja G, Dannaeus A, Foucard T, Graff-Lönnevig V, Johansson SGO \& Öhman H (1989) Effects of maternal diet during late pregnancy and lactation on the development of atopic diseases in infants up to eighteen months of age - in vivo results. Clinical and Experimental Allergy 19, 473-479.

Lönnerdal B (2000) Immunological considerations of breast milk. In Nutrition and Immunology, pp. 171-180 [ME Gershwin, JB German and CL Keen, editors]. Totowa, NJ: Humana Press.

Lu L \& Walker WA (2001) Pathologic and physiologic interactions of bacteria with the gastrointestinal epithelium. American Journal of Clinical Nutrition 73, Suppl., 1124S-1130S.

McClure SJ, McClure TJ \& Emery DL (1999) Effects of molybdenum intake on primary infection and subsequent challenge by the nematode parasite Trichostrongylus colubriformis in weaned Merino lambs. Research in Veterinary Science 67, 17-22.

Majamaa H, Isolauri E, Saxelin M \& Vesikari T (1995) Lactic acid bacteria in the treatment of acute rotavirus gastroenteritis. Journal of Pediatrics in Gastroenterology and Nutrition 20, 333-338.

Manhart N \& Roth E (2001) Influence of fructo-oligo-saccharides on Peyer's patch lymphocytes in healthy and endotoxemic mice. Clinical Nutrition 20, Suppl. 3, 14.

Manhart N, Vierlinger K, Spittler A, Bergmeister H \& Roth E (1999) Effects of orally administered glutamine on lymphocyte subpopulations in Peyer's patches in endotoxin boostered mice. Immunology Letters 69, 25·33 Abstr.

Manzano M, Abadía-Molina A, García-Olivares E, Gil A \& Rueda R (1999) Dietary nucleotides modify murine intestinal lymphocyte subpopulations at weaning. Immunology Letters 69, 44.6 Abstr.

Manzano M, Abadía-Molina A, García-Olivares E, Gil A \& Rueda R (2001) Dietary nucleotides induce Th1 and Th2 cytokine production by Peyer's patch lymphocytes in mice at weaning. Clinical Nutrition 20, Suppl. 3, 14.

Marteau PR, De Vrese M, Cellier CJ \& Schrezenmeir J (2001) Protection from gastrointestinal diseases with the use of probiotics. American Journal of Clinical Nutrition 73, Suppl., 430S-436S.

Mattsby-Baltzer I, Roseanu A, Motas C, Elvefors J, Engberg I \& Hanson LA (1996) Lactoferrin or a fragment thereof inhibits the endotoxin-induced interleukin-6 response in human monocytic cells. Pediatric Research 40, 257-262.

Millward DJ (1999) Requirements and role in diet. In Encyclopedia of Human Nutrition, pp. 1661-1679 [MJ Sadler, JJ Strain and B Caballero, editors]. London: Academic Press. 
Miura S, Tsuzuki Y, Hokari R \& Ishii H (1998) Modulation of intestinal immune system by dietary fat intake: relevance to Crohn's disease. Journal of Gastroenterology and Hepatology 13, 1183-1190.

Morales VM, Snapper SB \& Blumberg RS (1996) Probing the gastrointestinal immune function using transgenic and knockout technology. Current Opinion in Gastroenterology 12, 577-583.

Murch SH (2000) The immunologic basis for intestinal food allergy. Current Opinion in Gastroenterology 16. $552-557$.

Murch SH (2001) Toll of allergy reduced by probiotics. Lancet 357, 1057-1059.

Myrvik QN (1994) Immunolgy and nutrition. In Modern Nutrition in Health and Disease, pp. $632-662$ [ME Shills, JA Olson and M Shike, editors]. Philadelphia: Lea \& Febiger.

Nagakura T, Matsuda S, Shichiiyo K, Sugimoto H \& Hata K (2000) Dietary supplementation with fish oil rich in omega-3 polyunsaturated fatty acids in children with bronchial asthma. European Respiratory Journal 16, 861-865.

Nashar TO, Webb HM, Eaglestone S, Williams NA \& Hirst TR (1996) Potent immunogenicity of the B subunit of Escherichia coli heat-labile enterotoxin: receptor binding is essential and induces differential modulation of lymphocyte subsets. Proceedings of the National Academy of Sciences USA 93, 226-230.

Newberry RD, Stenson WF \& Lorenz RG (1999) Cyclooxigenase-2-dependent arachidonic acid metabolites are essential modulators of the intestinal immune response to dietary antigen. Nature Medicine 5, 900-906.

Oberhelman RA, Gilman RH, Sheen P, Taylor DN, Black RE, Cabrera L, Lescano AG, Meza R \& Madico G (1999) A placebo-controlled trial of Lactobacillus GG to prevent diarrhea in undernourished Peruvian children. Journal of Pediatrics 134, 15-20.

Ortaldo JR, Mason AT, Longo DL, Beckwith M, Creekmore SP \& McVicar DW (1996) T Cell activation via the disialoganglioside GD3: analysis of signal transduction. Journal of Leukocyte Biology 60, 533-539.

Pabst H \& Spady DW (1990) Effect of breastfeeding on antibody response to conjugate vaccine. Lancet 336, 269-270.

Pabst HF, Spady DW, Pilarski LM, Carson MM, Beeler JA \& Krezolek MP (1997) Differential modulation of the immune response by breast or formula feeding of infants. Acta Paediatrica 86, 1291-1297.

Pathmakanthan S, Meance S \& Edwards CA (2000) Probiotics: A review of human studies to date and methodological approaches. Microbial Ecology in Health and Disease, Suppl. 2, 10-30.

Pearce JL \& Hamilton JR (1974) Controlled trial of orally administered lactobacilli in acute infantile diarrhoea. Journal of Pediatrics 84, 261-262.

Pedone C, Bernabeau A, Postaire E, Bouley A \& Reinert P (1999) The effect of supplementation with milk fermented by Lactobacillus casei (strain DN-114 001) on acute diarrhoea in children attending day care centres. International Journal of Clinical Practice 53, 179-184.

Pickering LK, Granoff DM, Erickson JR, Masor ML, Cordle CT, Schaller JP, Winship TR, Paule CL \& Hilty MD (1998) Modulation of the immune system by human milk and infant formula containing nucleotides. Pediatrics 101, 242-249.

Puente R, García-Pardo LA, Rueda R, Gil A \& Hueso P (1996) Seasonal variations in the concentration of gangliosides and sialic acids in milk from different mammalian species. International Dairy Journal 6, 315-322.

Ragno V, Giampietro PG, Bruno G \& Businco L (1993) Allergenicity of milk protein hydrolysate formulae in children with cow's milk allergy. European Journal of Pediatrics 152, 760-762.

Raza S, Graham SM, Allen SJ, Sultana S, Cuevas L \& Hart CA (1995) Lactobacillus GG promotes recovery from acute nonbloody diarrhea in Pakistan. Pediatric Infectious Disease Journal 14, 107-111.

Redmon HP, Stapleton PP, Neary P \& Bourchier-Hayes D (1998) Immunonutrition: role of taurine. Nutrition 14 599-604.

Reilly E (1999) Selenium - Physiology, dietary sources and requirements. In Encyclopedia of Human Nutrition, pp. 1752-1758 [MJ Sadler, JJ Strain and B Caballero, editors]. London: Academic Press.

Rognum TO, Thrane PS, Stoltenberg L, Vege A \& Brandtzaeg P (1992) Development of intestinal mucosal immunity in fetal life and the first postnatal months. Pediatric Research 32, 145-149.

Rollwagen FM \& Baqar S (1996) Oral cytokine administration. Immunology Today 17, 548-550.

Rueda R \& Gil A (1998) Role of gangliosides in infant nutrition. In Lipids in Infant Nutrition, pp. 213-234 [Y-S Huang and AJ Sinclair, editors]. Champaign, IL: AOCS Press.

Rueda R \& Gil A (2000) Influence of dietary compounds on intestinal immunity. Microbial Ecology in Health and Disease Suppl. 2, 146-156.

Rueda R, Puente R, Hueso P, Maldonado J \& Gil A (1995) New data on content and distribution of gangliosides in human milk. Biological Chemistry Hoppe-Seyler 376, 723-727.

Rueda R, Sabatel JL, Maldonado J, Molina-Font JA \& Gil A (1998) Addition of gangliosides to an adapted milk formula modifies levels of fecal Escherichia coli in preterm newborn infants. Journal of Pediatrics 133, 90-94.

Saarinen UM \& Kajosaari M (1995) Prolonged breast-feeding as prophylaxis for atopic disease: prospective follow-up study until 17 years old. Lancet 346, 1065-1069.

Saarinen UM, Kajosaari M, Blackman A \& Siimes MA (1979) Prolonged breast-feeding as prophylaxis for atopic disease. Lancet ii, $163-168$.

Saavedra JM (2001) Clinical applications of probiotic agents. American Journal of Clinical Nutrition 73, Suppl., $1147 \mathrm{~S}-1151 \mathrm{~S}$.

Saavedra JM, Bauman NA, Oung I, Perman JA \& Yolken RH (1994) Feeding of Bifidobacterium bifidum and Streptococcus thermophilus to infants in hospital for prevention of diarrhoea and shedding of rotavirus. Lancet 344, 1046-1049. 
Sánchez-Pozo A, Rueda R, Fontana L \& Gil A (1998) Dietary nucleotides and cell growth. Trends in Comparative Biochemistry and Physiology 5,99-111.

Sanderson P, MacPherson GG, Jenkins CH \& Calder PC (1997) Dietary fish oil diminishes the antigen presentation activity of rat dendritic cells. Journal of Leukocyte Biology 62, 771-777.

Schiffrin EJ, Rochat F, Link-Amster H, Aeschlimann JM \& Donnet-Hughes A (1995) Immunomodulation of human blood cells following the ingestion of lactic acid bacteria. Journal of Dairy Science 78, 491-497.

Schmitz H \& Chevaux K (2000) Defining the role of dietary phytochemicals in modulating human immune function. In Nutrition and Immunology. Principles and Practice, pp. 107-118 [ME Gershwin, JB German and CL Keen, editors]. Totowa, NJ: Humana Press.

Sheehy T \& Morrissey PA (1999) Tocopherols - Physiology. In Encyclopedia of Human Nutrition, pp. 1878-1884 [MJ Sadler, JJ Strain and B Caballero, editors]. London: Academic Press.

Shirota K, Le Duy L, Joan S \& Jothy S (1990) Interleukin 6 and its receptor are expressed in human intestinal epithelial cells. Virchows Archive 58, 303-308.

Shornikova AV, Casas IA, Isolauri E, Mykkanen H \& Vesikari T (1997b) Lactobacillus reuteri as a therapeutic agent in acute diarrhoea in young children. Journal of Pediatric Gastroenterology and Nutrition 24, 399-404.

Shornikova AV, Casas IA, Mykkanen H, Salo E \& Vesikari T (1997c) Bacteriotherapy with Lactobacillus reuteri in rotavirus gastroenteritis. Pediatric Infectious Diseases Journal 16, 1103-1107.

Shornikova AV, Isolauri E, Burkanova L, Lukovnikova S \& Vesikari T (1997a) A trial in the Karelian Republic of oral rehydration and Lactobacillus GG for treatment of acute diarrhoea. Acta Paediatrica 86, 460-465.

Sigurs N, Hattevig G \& Kjellman B (1992) Maternal avoidance of eggs, cow's milk and fish during lactation: effect on allergic manifestations, skin-prick tests and specific $\operatorname{IgE}$ antibodies in children at age 4 hours. Pediatrics 89, 735-739.

Solomons NW \& Keusch GT (2000) Clinical issues. Childhood illnesses, vaccinations, and nutritional status. In Nutrition and Immunology, pp. 181-194 [ME Gershwin, JB German and CL Keen, editors]. Totowa, NJ: Humana Press.

Stahl B, Thurl S, Zeng J, Karas M, Hillenkamp F, Steup M, Sawatzki G (1994) Oligosaccharides from human milk as revealed by matrix-associated laser desorption/ionization mass spectrometry. Analytical Biochemistry 223, $218-226$.

Steidler L, Hans W, Schotte L, Neirynck S, Obermeier F, Falk W, Fiers W \& Remaut E (2000) Treatment of murine colitis by Lactococcus lactis secreting interleukin-10. Science 289, 1352-1355.

Strimas JH \& Chi DS (1988) Significance of Ig E level in amniotic fluid and cord blood for the prediction of allergy. Annals of Allergy 61, 133-136.

Strober W \& Ehrhardt RO (1994) Regulation of IgA cell development. In Handbook of Mucosal Immunology, pp. 159-176 [PL Ogra, MD Strober, J Mestecky, JR McGhee, ME Lamm and J Bienenstock, editors]. San Diego, CA: Academic Press.

Sudo N, Sawamura S, Tanaka K, Aiba Y, Kubo C \& Koga Y (1997) The requirement of intestinal bacterial biota for the development of an Ig E production system fully susceptible to oral tolerance induction. Journal of Immunology 159, 1739-1745.

Sweeney B, Puri P \& Reen DJ (2001) Polyunsaturated fatty acids influence neonatal monocyte survival. Pediatric Surgery International 17, 254-258.

Szajewska H \& Mrukowicz JZ (2001) Probiotics in the treatment and prevention of acute infectious diarrhea in infants and children: a systematic review of published randomized, double blind, placebo-controlled trials. Journal of Pediatric Gastroenterology and Nutrition 33, S17-S25.

Tanaka M, Lee K, Martínez-Augustín O, He Y, Sanderson IR \& Walker A (1996) Exogenous nucleotides alter the proliferation, differentiation and apoptosis of human small intestinal epithelium. Journal of Nutrition 126, 424-433.

Telemo E \& Hanson LA (1996) Antibodies in milk. Journal of Mammary Gland Biology and Neoplasia 1, $243-249$.

Terada S, Takizawa M, Yamamoto S, Ezaki O, Itakura H \& Akagawa KS (2001) Suppressive mechanisms of EPA on human T cell proliferation. Microbiology and Immunology 45, 473-481.

Teraguchi S, Shin K, Ozawa K, Nakamura S, Fukuwatari Y, Tsuyuki S, Namihira H \& Shimamura S (1995) Bacteriostatic effect of orally administered bovine lactoferrin on proliferation of Clostridium species in the gut of mice fed bovine milk. Applied and Environmental Microbiology 61, 501-506.

Terrazas LI, Walsh KL, Piskorska D, McGuire E \& Harn DA (2001) The schistosome oligosaccharide lacto-N-neotetraose expands Gr1 (+) cells that secrete anti-inflammatory cytokines and inhibit proliferation of naive CD4 (+) cells: a potential mechanism for immune polarization in helminth infections. Journal of Immunology 167, 5294-5303.

Tojo M, Oikawa T, Morikawa Y, Yamashita N, Iwata S, Satoh Y, Hanada J \& Tanaka R (1987) The effects of Bifidobacterium breve administration on campylobacter enteritis. Acta Paediatrica Japan 29, 160-167.

Uauy R, Quan R \& Gil A (1996) Nucleotides in infant nutrition. In Nutritional and Biological Significance of Dietary Nucleotides and Nucleic Acids, pp. 169-180 [A Gil and R Uauy, editors]. Barcelona: Doyma.

Udall JN, Colony P, Fritze L, Pang K, Trier JS \& Walker JA (1981) Development of the gastrointestinal mucosal barrier. II. The effect of natural versus artificial feeding on intestinal permeability to macromolecules. Pediatric Research 15, 245-249.

Van Buren CT, Kulkarni AD, Fanslow WC \& Rudoplh FB (1985) Dietary nucleotides: A requirement for helper/inducer T lymphocytes. Transplantation 40, 694-697.

Vanderhoof JA (2000) Probiotics and intestinal inflammatory disorders in infants and children. Journal of Pediatric Gastroenterology and Nutrition, S34-S38.

Vázquez E (2000) Influence of gangliosides on the mouse intestinal immune system. PhD thesis, University of Granada. 
Vázquez E, Gil A, García-Olivares E \& Rueda R (1999) Dietary gangliosides increase the number of intestinal IgAsecreting cells in weaning mice. Immunology Letters 69, 44.7 Abstr.

Vázquez E, Gil A \& Rueda R (2001) Dietary gangliosides positively modulate the percentages of Th1 and Th2 lymphocyte subsets in small intestine of mice at weaning. BioFactors 15, 1-9.

Veltkamp C, Tankonogy SL, Schultz M \& Sartor RB (1999) Lactobacillus plantarum is superior to Lactobacillus GG preventing colitis in IL-10 deficient mice. Gastroenterology 116, A838.

Wold AE \& Adlerberth I (1998) Does breastfeeding affect the infant's immune responsiveness? Acta Paediatrica 87, 19-22.

Wold AE \& Hanson LA (1994) Defense factors in human milk. Current Opinion in Gastroenterology 10, $652-658$.

Xu D, Lu Q \& Deitch EA (1998) Elemental diet-induced bacterial translocation associated with systemic and intestinal immune suppression. Journal of Parenteral and Enteral Nutrition 22, 37-41.

Yolken RH, Peterson JA, Vonderfecht SL, Fouts ET, Midthun K \& Newburg DS (1992) Human milk mucin inhibits rotavirus replication and prevents experimental gastroenteritis. Journal of Clinical Investigation 90, 1984-1991.

Yuasa H, Scheinberg DA \& Houghton AN (1990) Gangliosides of T lymphocytes: evidence for a role in T-cell activation. Tissue Antigens 36, 47-56. 